\title{
Pulmonary Hypertension Secondary to COPD
}

\author{
Adil Shujaat, Abubakr A. Bajwa, and James D. Cury \\ Division of Pulmonary, Critical Care \& Sleep Medicine, University of Florida College of Medicine-Jacksonville, 655 West 8 th Street, \\ Jacksonville, FL 32209, USA
}

Correspondence should be addressed to Adil Shujaat, adil.shujaat@jax.ufl.edu

Received 2 May 2012; Accepted 4 July 2012

Academic Editor: Kiriakos Karkoulias

Copyright ( $) 2012$ Adil Shujaat et al. This is an open access article distributed under the Creative Commons Attribution License, which permits unrestricted use, distribution, and reproduction in any medium, provided the original work is properly cited.

\begin{abstract}
The development of pulmonary hypertension in COPD adversely affects survival and exercise capacity and is associated with an increased risk of severe acute exacerbations. Unfortunately not all patients with COPD who meet criteria for long term oxygen therapy benefit from it. Even in those who benefit from long term oxygen therapy, such therapy may reverse the elevated pulmonary artery pressure but cannot normalize it. Moreover, the recent discovery of the key roles of endothelial dysfunction and inflammation in the pathogenesis of $\mathrm{PH}$ provides the rationale for considering specific pulmonary vasodilators that also possess antiproliferative properties and statins.
\end{abstract}

\section{Introduction}

Pulmonary hypertension $(\mathrm{PH})$ secondary to chronic obstructive pulmonary disease (COPD) is placed in group 3 of the WHO classification of $\mathrm{PH}$, that is, $\mathrm{PH}$ associated with lung diseases and/or hypoxemia (Table 1) [1]. PH in COPD has been variably defined as resting mean pulmonary artery pressure (mPAP) > 20-25 mm Hg. PH in COPD adversely affects survival and exercise capacity and is associated with an increased risk of acute exacerbations. Recent studies have shown that endothelial dysfunction and systemic inflammation also play important roles in the pathogenesis of $\mathrm{PH}$. The recent development of specific pulmonary vasodilators with antiproliferative properties has stimulated an immense interest in studying such drugs in $\mathrm{PH}$ secondary to COPD.

\section{Prevlence of PH in COPD}

The prevalence of $\mathrm{PH}$ in stable COPD varies from 20 to $91 \%$ depending on the definition of $\mathrm{PH}$ ( $\mathrm{mPAP}>20$ versus $>25 \mathrm{~mm} \mathrm{Hg}$ ), the severity of COPD (forced expiratory volume in the first second: FEV1), and the method of measuring the pulmonary artery pressure (echocardiography versus right heart catheterization) [2-7].

In severe COPD patients with or without resting $\mathrm{PH}$, steady-state exercise may raise pulmonary artery pressure
(PAP) to about twice the level of its resting value [8]. In severe COPD activities of daily living such as climbing stairs or walking can induce transient $\mathrm{PH}$.

In patients with severe COPD, oxygen saturation may fall during REM sleep by 20-30\% [9, 10] and PAP may rise by as much as $20 \mathrm{~mm} \mathrm{Hg}$ [11].

During an acute exacerbation of COPD, PAP may rise by as much as $20 \mathrm{~mm} \mathrm{Hg}$ and return to its baseline after recovery $[12,13]$.

\section{Significance of PH in COPD}

In the era before the widespread availability of long-term oxygen therapy (LTOT) it was well known that the presence of $\mathrm{PH}$ was associated with poor prognosis in COPD. However, even on LTOT the best prognostic factor is not the FEV1, nor the degree of hypoxemia or hypercapnia, but the level of mPAP. The 5-year survival rate is only $36 \%$ in patients with initial mPAP > $25 \mathrm{~mm} \mathrm{Hg}$ compared to $62 \%$ in those with initial $\mathrm{mPAP} \leq 25 \mathrm{~mm} \mathrm{Hg}$ [14]. Moreover, Weitzenblum et al. [15], who followed up hypoxemic COPD patients with $\mathrm{PH}$ on LTOT for a period of 6 years, demonstrated a reversal but not normalization of the PAP. Recently, Zieliński et al. [16] also reported similar findings in a larger study.

$\mathrm{PH}$ is also an independent predictor of exercise capacity. Sims et al. [17] found that in 362 severe COPD patients 
TABLe 1: Updated clinical classification of pulmonary hypertension (Dana Point, 2008) [1].

(1) Pulmonary arterial hypertension (PAH)

(1.1) Idiopathic PAH

(1.2) Heritable

(1.2.1) BMPR2

(1.2.2) ALK1, endoglin (with or without hereditary hemorrhagic telangiectasia)

(1.2.3) Unknown

(1.3) Drug- and toxin-induced

(1.4) Associated with

(1.4.1) Connective tissue diseases

(1.4.2) HIV infection

(1.4.3) Portal hypertension

(1.4.4) Congenital heart disease

(1.4.5) Schistosomiasis

(1.4.6) Chronic hemolytic anemia

(1.5) Persistent pulmonary hypertension of the newborn

(i) Pulmonary venoocclusive disease (PVOD) and/or pulmonary capillary hemangiomatosis ( $\mathrm{PCH})$

(2) Pulmonary hypertension owing to left-heart disease

(2.1) Systolic dysfunction

(2.2) Diastolic dysfunction

(2.3) Valvular disease

(3) Pulmonary hypertension owing to lung disease and/or hypoxia

(3.1) Chronic obstructive pulmonary disease (COPD)

(3.2) Interstitial lung disease

(3.3) Other pulmonary diseases with mixed restrictive and obstructive pattern

(3.4) Sleep-disordered breathing

(3.5) Alveolar hypoventilation disorders

(3.6) Chronic exposure to high altitude

(3.7) Developmental abnormalities

(4) Chronic thromboembolic pulmonary hypertension (CTEPH)

(5) Pulmonary hypertension with unclear multifactorial mechanisms

(5.1) Hematologic disorders: myeloproliferative disorders, splenectomy

(5.2) Systemic disorders: sarcoidosis, pulmonary Langerhans cell histiocytosis, lymphangioleiomyomatosis, neurofibromatosis, vasculitis

(5.3) Metabolic disorders: glycogen storage disease, Gaucher disease, thyroid disorders

(5.4) Others: tumoral obstruction, fibrosing mediastinitis, chronic renal failure on dialysis

Simonneau [1].

who underwent right-heart catheterization (RHC) as part of evaluation for lung transplantation, higher pulmonary artery pressures were associated with shorter 6-minute walk distance (6MWD) even after controlling for demographics, anthropomorphics, severity of airflow obstruction, and pulmonary artery wedge pressure (PAWP). They found an $11 \mathrm{~m}$ decline in 6MWD for every $5 \mathrm{~mm}$ rise in $\mathrm{mPAP}(95 \% \mathrm{CI}$ $21,0.7 ; P=0.04)$. In another study Cuttica et al. [7] reviewed the records of 1154 COPD patients listed for lung transplantation and found an association between mPAP and 6MWD independent of lung function and PAWP $(\beta=$ $-1.33 ; P=0.01)$.

Lastly, it has been shown that a mPAP $>18 \mathrm{~mm} \mathrm{Hg}$ is associated with an increased risk of severe acute exacerbation in patients with moderate to severe COPD [18].

\section{Pathophysiology of PH Secondary to COPD}

In hemodynamic terms PAP depends upon cardiac output (CO), pulmonary vascular resistance (PVR), and pulmonary artery wedge pressure (PAWP) (Figure 1). Resting $\mathrm{PH}$ in COPD results predominantly from an elevated PVR whereas $\mathrm{PH}$ during exercise results predominantly from an increase in CO in the face of a relatively "fixed" PVR, that is, there is reduced recruitability and distensibility of pulmonary vessels [19]. Hyperinflation increases PVR [20] as well as PAWP [20, 21] and PAP [20], particularly during exercise.

Traditionally, elevated PVR in COPD has been considered to be the consequence of hypoxic pulmonary vasoconstriction and vascular remodeling, destruction of the pulmonary vascular bed by emphysema, polycythemia, and hyperinflation. Recently, it has been recognized that endothelial dysfunction and systemic inflammation also play key roles in the pathogenesis of $\mathrm{PH}$ (Figure 2). In fact it is believed that the initial event in the natural history of $\mathrm{PH}$ in COPD could be endothelial dysfunction caused by cigarette smoke [22].

4.1. Pulmonary Vasoconstriction. Hypoxic constriction of the small muscular pulmonary arteries [23] is a protective mechanism to divert blood flow from hypoxic alveoli to 


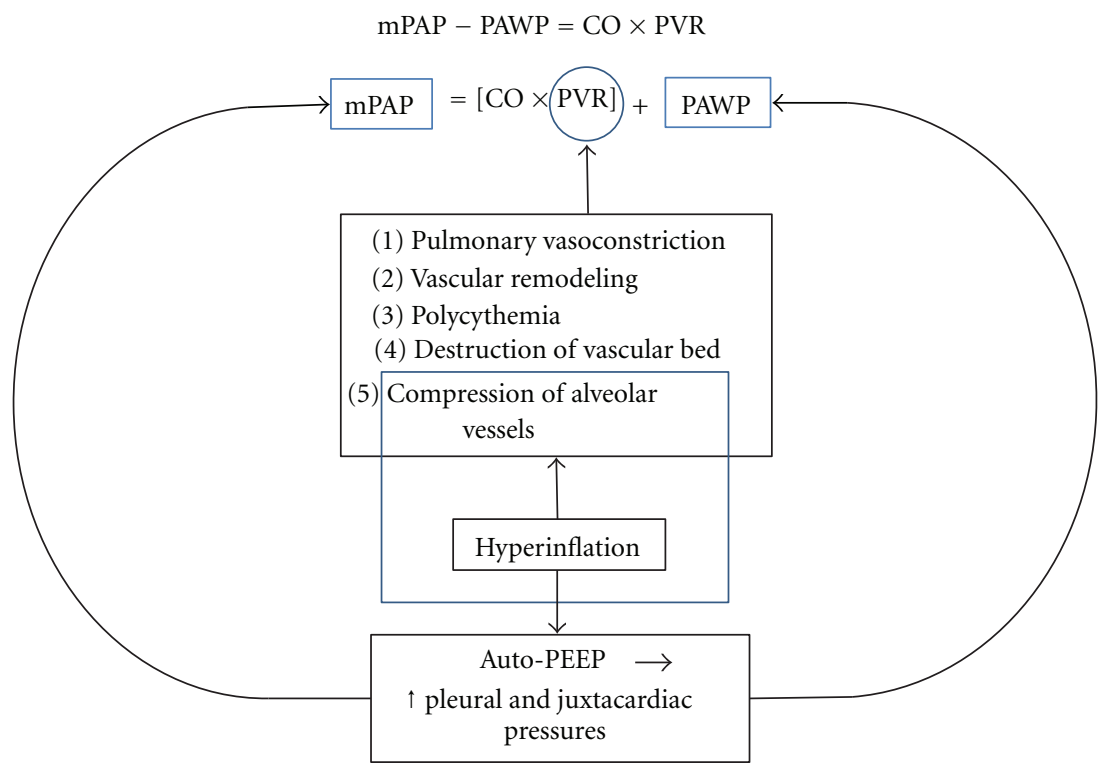

FIGURE 1: Pathophysiology of PH in COPD. mPAP: mean pulmonary artery pressure, PAWP: pulmonary artery wedge pressure, CO: cardiac output, PVR: pulmonary vascular resistance, PEEP: positive end-expiratory pressure.

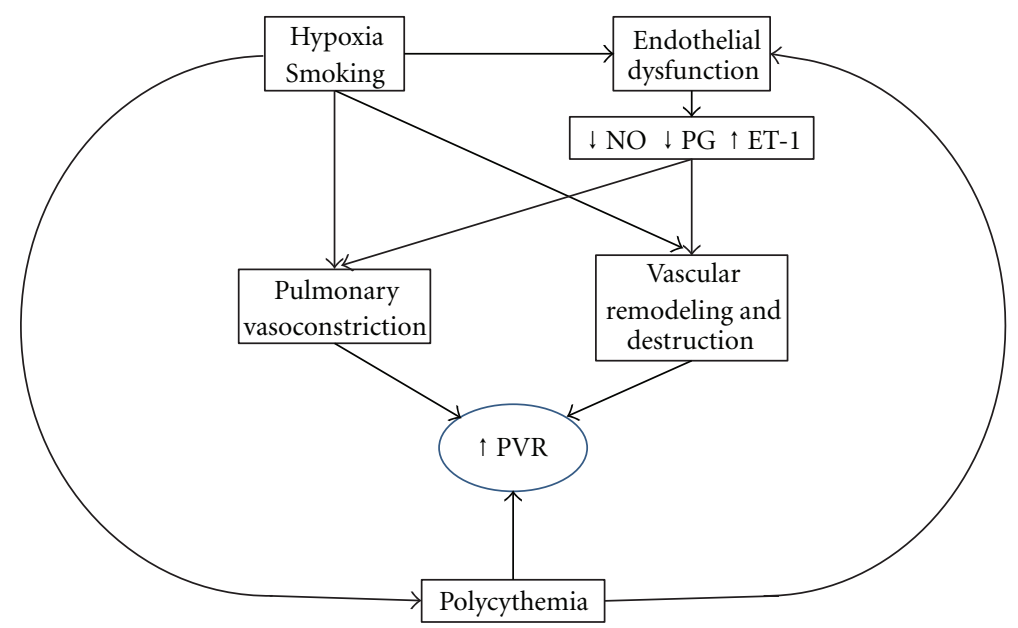

FIGURe 2: Pathophysiology of elevated PVR in COPD. PVR: pulmonary vascular resistance, NO: nitric oxide, PG: prostaglandin, ET-1: endothelin-1.

better ventilated alveoli and reduce ventilation-perfusion mismatch [24]. However, when alveolar hypoxia is diffuse, such as in severe COPD, it causes generalized pulmonary vasoconstriction and consequently raises the PVR. Persistent hypoxia leads to pulmonary vascular remodeling [25] which contributes to the PVR.

4.2. Pulmonary Vascular Remodeling. Vascular remodeling in COPD patients is seen at all stages of the disease and is characterized by intimal fibrosis and proliferation of longitudinal smooth muscle in the muscular pulmonary arteries and arterioles, and neomuscularization of pulmonary arterioles [2628]. These pulmonary vascular changes also occur in patients with mild COPD and no hypoxia and in smokers with no airway obstruction. This suggests that mechanisms other than hypoxia also play an important role in the pathogenesis of vascular remodeling [29].

However, pathologic studies in COPD have not shown complex lesions, which are frequently encountered in patients with pulmonary arterial hypertension [30], such as plexiform lesions (irregular mass of endothelial cells) or angiomatoid lesions, characteristic of severe $\mathrm{PH}$.

4.3. Endothelial Dysfunction. The normal endothelium plays an important role in modulating pulmonary vasomotor tone and cellular proliferation. Nitric oxide (NO) produced by endothelial NO synthase (eNOS) has vasodilator and antiproliferative properties. Prostacyclin produced by the activity 
of prostacyclin synthase is another vasodilator that also protects against vascular remodeling. Countering vasodilatation is endothelium-derived endothelin-1 (ET-1). Endothelial dysfunction caused by smoking, products of inflammation, hypoxia, and shear stress results in altered production of these mediators of tone and/or proliferation, and consequently pulmonary vasoconstriction and vascular remodeling with the latter perpetuating endothelial dysfunction and creating a vicious cycle. In patients with COPD and $\mathrm{PH}$ there is a reduction in the synthesis and/or release of $\mathrm{NO}$ from the lung [31]. In COPD there is a reduction in the expression of prostacyclin synthase mRNA [32], and in patients with secondary pulmonary hypertension there is an excessive expression of endothelin-1 (ET-1) [33]. Arterial ET-1 also increases shortly after episodes of nocturnal oxygen desaturation in patients with COPD and remains higher during the day in these subjects [34].

4.4. Inflammation. Cigarette smoking induces a CD8+ Tlymphocyte infiltration of the adventitia of muscular pulmonary arteries, which correlates with both the endothelium-dependent relaxation and the intimal thickness, suggesting the potential involvement of an inflammatory process in the pathogenesis of pulmonary vascular abnormalities in the early stage of COPD [35].

Systemic inflammation is a known component of COPD $[36,37]$ and inflammation may contribute to the pathogenesis of PH. Chaouat et al. [38] showed that elevated circulating levels of the proinflammatory cytokine interleukin-6 (IL-6) directly correlated with elevations in mPAP $(r=0.39 ; P<$ 0.001). Moreover, C-reactive protein levels have also been shown to correlate with both PAP and levels of ET-1 [39].

4.5. Destruction of the Pulmonary Vascular Bed. Destruction of the pulmonary vascular bed by emphysema reduces the total cross-sectional area of the pulmonary circulation and increases the total PVR when the remaining capacitance vessels are abnormal and unable to accommodate the increased diverted pulmonary blood flow at rest and the increased $\mathrm{CO}$ during exercise.

A hypercoagulable state has also been described in patients with COPD $[40,41]$. There appears to be an increased frequency of deep venous thrombosis and pulmonary embolism in acute exacerbations of COPD [41-43] and histopathologically thrombotic lesions have been detected in lung tissue from patients with severe emphysema undergoing lung-volume reduction surgery [44]. It is postulated that the inflammatory aspects of the so-called COPD exacerbation may trigger a hypercoagulable state and increase the risk of thrombosis including in situ thrombosis.

4.6. Polycythemia. Polycythemia not only increases the viscosity of blood and the resistance to blood flow through the pulmonary circulation [45] but also augments hypoxic pulmonary vasoconstriction by causing a local deficiency of NO which may be related to the excessive removal of NO from the pulmonary circulation by the large amount of hemoglobin $[46,47]$.
4.7. Genetic Factors. The pulmonary vascular response to hypoxia is genetically determined. Serotonin (5-hydroxytryptamine, 5-HT) and its transporter (5-HTT) play a role in pulmonary artery smooth muscle cell (PASMC) proliferation and vascular remodeling. The severity of $\mathrm{PH}$ in hypoxic COPD patients depends upon 5-HTT gene polymorphism. $\mathrm{PH}$ is most severe in patients carrying the LL genotype, which is associated with higher levels of 5-HTT expression in PASMCs [48]. ACE is present in very high concentrations in the lungs and its activity is further increased by hypoxia [49]. ACE is a vasoconstrictor and mediator of PASMC proliferation. The ACE DD genotype is associated with increased circulating and tissue concentrations of ACE. Moreover, the ACE DD genotype is associated with exaggerated $\mathrm{PH}$ during exercise in COPD patients [50].

4.8. Hyperinflation. Severe emphysema with air-trapping and hyperinflation is associated with intrinsic positive endexpiratory pressure of $5-7.5 \mathrm{~cm} \mathrm{H}_{2} \mathrm{O}$ [51]. The positive alveolar pressure throughout respiration contributes to the high PVR [20] as well as increases both PAWP [20, 21] and PAP [20]. This mechanism may assume a more important role in development of $\mathrm{PH}$ during exercise and in patients with severe emphysema who are not hypoxemic.

\section{Right and Left Ventricular Function in PH Secondary to COPD}

In response to the increased PVR the right ventricle (RV) gradually undergoes hypertrophy and dilatation-cor pulmonale. This increase in RV end-diastolic volume (RVEDV), that is, preload, to maintain a normal stroke volume (SV) accounts for the reduced RV ejection fraction (EF). RV contractility, as assessed by end systolic pressure-volume relation, is normal in stable COPD patients and the RV operates on an extension of the normal RV function Frank-Starling curve [52].

Changes in RV SV must invariably alter left ventricular (LV) preload, because the two ventricles are serially linked through the pulmonary vasculature. LV preload can also be directly altered by changes in RVEDV by the mechanism of ventricular interdependence. The increased RVEDV in cor pulmonale induces a shift of the interventricular septum into the LV and decreases LV diastolic compliance but this does not adversely affect LV SV because the increased RV systolic pressure in cor pulmonale also pushes the septum into the LV towards its free wall to empty the LV. This "help" from the RV in systole tends to preserve LVEF in emphysematous patients with severe RV hypertrophy $[53,54]$.

More importantly, hyperinflation, particularly during exercise, has the effect of compressing the two ventricles into each other $[55,56]$. This decreases RV preload and results in lower SV and CO. Even in less severe COPD the development of hyperinflation during exercise can similarly lead to a reduction in RV preload and CO.

During an acute exacerbation of COPD, the RV may actually fail, that is, end-diastolic pressure and volume rise and RVEF falls, resulting in peripheral edema and systemic 
congestion $[57,58]$. However, these changes may not be associated with a rise in PAP suggesting that other factors may be operating to reduce RV contractility [57]. Moreover, an acute exacerbation may be associated with peripheral edema in the absence of RV failure [58].

The pathogenesis of edema formation in COPD is complex. Renal blood flow is reduced, the renin-angiotensin system is activated, renal dopamine output is reduced, and plasma ANP level is elevated leading to increase in proximal renal tubular sodium reabsorption $[59,60]$. Sodium retention is enhanced by hypercapnia and ameliorated by long-term oxygen therapy in hypoxemic patients [61]. True right heart failure is characterized by raised jugular venous pressures, congestive hepatomegaly, and peripheral edema.

\section{Degree of PH in COPD}

Resting $\mathrm{PH}$ in stable COPD is usually mild to moderate (mPAP $20-35 \mathrm{~mm} \mathrm{Hg}$ ) and is usually not seen until the disease is advanced $(\mathrm{FEV} 1<50 \%)$. Severe PH $(\mathrm{mPAP}>35-$ $45 \mathrm{~mm} \mathrm{Hg})$ is rare $(3 \%-13 \%)[5-7,62]$ and should prompt a search for an additional cause of $\mathrm{PH}$, for example, left heart disease, obstructive sleep apnea (OSA), pulmonary embolism (PE).

6.1. Severe "Disproportionate" $P H$. Recently a group of patients with severe PH (mPAP $>40 \mathrm{~mm} \mathrm{Hg}$ ) and extremely poor prognosis has been recognized. The 5-year survival is $15 \%$ versus $55 \%$ in those with less severe $\mathrm{PH}$ (mPAP 20 $40 \mathrm{~mm} \mathrm{Hg}$ ) [62]. Such patients are characterized by mild to moderate airway obstruction, a very low diffusing capacity, severe hypoxemia, and hypocapnia (Table 2) [62]. Thabut et al. [6] have also described a similar group (mPAP > $45 \mathrm{~mm} \mathrm{Hg}$ ). However, such severe $\mathrm{PH}$ in COPD in the absence of an alternative explanation is rare $(1-3.7 \%)[6,62]$ and suggests the existence of a "vascular phenotype" or concomitant idiopathic pulmonary arterial hypertension.

\section{Diagnosis of PH in COPD}

$\mathrm{PH}$ secondary to COPD should be suspected in patients with progressive dyspnea on exertion with stable airway obstruction or in patients with mild to moderate airway obstruction with a very low diffusing capacity, severe hypoxemia, and hypocapnia $[6,62]$.

A diagnosis of PH in COPD (Table 3) should prompt a search for other causes of $\mathrm{PH}$, particularly left heart dysfunction, OSA, and PE before attributing the $\mathrm{PH}$ to COPD.

7.1. Clinical Features. The clinical exam lacks sensitivity and specificity. Hyperinflation reduces the yield of cardiac auscultation for the classic signs of $\mathrm{PH}$ and right heart failure, that is, loud P2, S3 gallop, the systolic murmur of tricuspid regurgitation. Peripheral edema can be present in the absence of right heart failure in COPD and is not diagnostic of right heart failure.

7.2. CPET. Although cardiopulmonary exercise test (CPET) characteristics show a large overlap in COPD patients with and without $\mathrm{PH}$, the existence of $\mathrm{PH}$ in COPD (defined as $\mathrm{mPAP}>25 \mathrm{~mm} \mathrm{Hg}$ ) is associated with a significantly reduced ventilatory efficiency during CPET. However, a low $\mathrm{SpO}_{2}$ at rest and a further decrease during exercise similarly suggest the presence of PH in COPD [63].

7.3. Chest X-Ray. An increase in the diameter of the right descending pulmonary artery to $>16 \mathrm{~mm}$ on the PA projection, combined with an increase in the diameter of the left descending pulmonary artery of $>18 \mathrm{~mm}$ on the left lateral projection, has a sensitivity $98 \%$ for identifying $\mathrm{PH}[64]$.

7.4. ECG. Electrocardiographic criteria for the detection of RV hypertrophy have good specificity, but the sensitivity for RV hypertrophy is only 25 to $40 \%$. The criteria include the following: (a) right axis deviation ( $>100$ degrees without right bundle branch block), (b) $\mathrm{R}$ or $\mathrm{R}^{\prime}>\mathrm{S}$ in $\mathrm{V} 1$, (c) $\mathrm{R}<\mathrm{S}$ in $\mathrm{V} 6,(\mathrm{~d}) \mathrm{R}$ in $\mathrm{V} 1+\mathrm{S}$ in $\mathrm{V} 5$ or $\mathrm{V} 6=10 \mathrm{~mm}$, (e) $\mathrm{R}$ in $\mathrm{V} 1=$ $7 \mathrm{~mm}$, (f) $\mathrm{R}$ in $\mathrm{V} 1=15 \mathrm{~mm}$ with right bundle branch block, and $(\mathrm{g})$ right atrial enlargement [52].

However, ECG may reveal other findings such as left atrial enlargement (LAE), left ventricular hypertrophy $(\mathrm{LVH})$, or myocardial infarction in the past that suggests an alternative cause of $\mathrm{PH}$.

The presence of S1 Q3 T3 (S wave in lead I, Q wave in lead III, and T wave inversion in lead III on ECG-S1, Q3, T3) or right atrial overload pattern (i.e., $\mathrm{P}$ wave axis of +90 degrees or more) implies a poor prognosis [65].

7.5. ECHO. Hyperinflation precludes optimal visualization of the heart. In a cohort of lung transplant candidates estimation of systolic PAP (sPAP) was possible in only $38 \%$ of the 253 patients with COPD. Hyperinflation with a residual volume $>150 \%$ lessened the likelihood of sPAP estimation. Sensitivity, specificity, negative predictive value (NPV), and positive predictive value (PPV) of sPAP estimated by ECHO for the diagnosis of $\mathrm{PH}$ (defined as sPAP $>45 \mathrm{~mm} \mathrm{Hg}$ estimated by ECHO or measured by RHC) were 76, 65, 93, and $32 \%$, respectively. In the absence of sPAP estimation, figures for RV abnormalities were $84,56,96$, and $22 \%$ respectively. It is important to realize that there was a discordance of $>10 \mathrm{~mm} \mathrm{Hg}$ between estimated and measured sPAP in 52\% of patients, and in $28 \%$, the discordance was $>20 \mathrm{~mm} \mathrm{Hg}$ [66]. Although the NPV of ECHO is high enough to exclude $\mathrm{PH}$ when the heart is adequately visualized, the presence of a high sPAP or RV abnormalities requires confirmation by RHC unless the ECHO shows left heart disease, for example, low LVEF, high LV filling pressure, LVH, left atrial enlargement, valvular incompetence.

Alternatively, transcutaneous Doppler US can be used to measure jugular vein flow velocity. Matsuyama et al. [67] showed that the ratio of diastolic flow (Df) to systemic flow (Sf) velocity showed a significant correlation with mPAP in COPD patients $(r=0.844, P<0.0001)$. The sensitivity was $71.4 \%$, and the specificity $95.3 \%$ (cut-off ratio $=1.0$ ). Jugular venous Doppler US could be performed in all patients while other cardiac echo methods could not be performed in all patients. The specificity of the methods used was higher than other cardiac echo methods [67]. 
TABLE 2: Comparison of 2 groups of COPD patients with PH.

\begin{tabular}{|c|c|c|c|}
\hline & Severe PH Group (mPAP $\geq 40 \mathrm{~mm} \mathrm{Hg}) N=11$ & Less severe PH (mPAP $20-40 \mathrm{~mm} \mathrm{Hg}) N=16$ & $P$ value \\
\hline FEV1 (\% predicted) & $50(44-56)$ & $27(23-34)$ & $<0.01$ \\
\hline $\mathrm{DLCO}(\mathrm{mL} / \mathrm{min} / \mathrm{mm} \mathrm{Hg})$ & $4.6(4.2-6.7)$ & $10.3(8.9-12.8)$ & $<0.01$ \\
\hline $\mathrm{PaO}_{2}(\mathrm{~mm} \mathrm{Hg})$ & $46(41-53)$ & $56(54-64)$ & $<0.01$ \\
\hline $\mathrm{PaCO}_{2}(\mathrm{~mm} \mathrm{Hg})$ & $32(28-37)$ & $47(44-49)$ & $<0.01$ \\
\hline RAP (mm Hg) & $7(5-9)$ & $3(1.3-4)$ & $<0.01$ \\
\hline mPAP (mm Hg) & $48(46-50)$ & $25(22-27)$ & $<0.01$ \\
\hline PAWP (mm Hg) & $6(4-7)$ & $7(6.5-7.5)$ & NS \\
\hline $\mathrm{CI}\left(\mathrm{L} / \mathrm{min} / \mathrm{m}^{2}\right)$ & $2.3(1.8-2.5)$ & $2.8(2.4-3.1)$ & $<0.01$ \\
\hline TPR (Wood units/m²) & $21.3(17.6-26.6)$ & $9(7.4-9.9)$ & $<0.01$ \\
\hline
\end{tabular}

Table adapted from $[63]$.

PH: pulmonary hypertension, FEV1: forced expiratory volume in the first second, DLCO: diffusing capacity for carbon monoxide, $\mathrm{PaO}_{2}$ : arterial oxygen tension, $\mathrm{PaCO}_{2}$ : arterial carbon dioxide tension, RAP: right atrial pressure, mPAP: mean pulmonary artery pressure, CI: cardiac index, TPR: total pulmonary resistance.

TABLE 3: Various approaches to the diagnosis of PH in COPD.

\begin{tabular}{|c|c|c|}
\hline Modality & Advantages & Disadvantages \\
\hline ECG & $\begin{array}{l}\text { Noninvasive, cheap, and readily available. } \\
\text { High specificity for RVH. } \\
\text { ECG may reveal other findings such LAE, LVH, or old MI that suggests an } \\
\text { alternative cause of } \mathrm{PH}\end{array}$ & Absence of RVH does not rule out PH. \\
\hline CXR & $\begin{array}{l}\text { Non-invasive, cheap, and readily available. } \\
\text { An } \uparrow \text { in the diameter of the right descending pulmonary artery to } \\
>16 \mathrm{~mm} \text { on the PA projection, combined with an } \uparrow \text { in the diameter of the } \\
\text { left descending pulmonary artery of }>18 \mathrm{~mm} \text { on the left lateral projection, } \\
\text { has a high sensitivity of } 98 \% \text { for PH }\end{array}$ & $\begin{array}{l}\text { Normal-sized pulmonary artery does not rule } \\
\text { out PH. }\end{array}$ \\
\hline BNP & Requires only a blood draw, is cheap and readily available. & $\begin{array}{l}\uparrow \mathrm{BNP} \text { also correlated with lower } \mathrm{PaO}_{2} \\
\text { suggesting that BNP can also be released in } \\
\text { response to hypoxia. More studies are needed. }\end{array}$ \\
\hline eNO & Non-invasive. & $\begin{array}{l}\text { Expensive, not widely available and has been } \\
\text { tested in only one study. }\end{array}$ \\
\hline $\mathrm{ECHO}$ & $\begin{array}{l}\text { High NPV of sPAP or RV abnormalities ( } 93 \% \text { and } 96 \% \text {, resp.) makes it an } \\
\text { excellent screening test. } \\
\text { Moreover, it provides additional data for example, LVEF, LV filling } \\
\text { pressures, valvular function. }\end{array}$ & $\begin{array}{l}\text { Hyperinflation may preclude optimal } \\
\text { visualization of the heart. } \\
\text { Although the NPV is high enough to exclude } \\
\mathrm{PH} \text {, the presence of a high sPAP or RV } \\
\text { abnormalities requires confirmation by RHC. }\end{array}$ \\
\hline Chest CT & $\begin{array}{l}\text { Non-invasive, widely available. } \\
\text { High PPV of } 95 \%-96 \% \text { for PH. } \\
\text { LAE could suggest left heart dysfunction. }\end{array}$ & $\begin{array}{l}\text { Expensive. } \\
\text { Radiation exposure. } \\
\text { Normal sized pulmonary artery does not rule } \\
\text { out PH. }\end{array}$ \\
\hline Cardiac MRI & $\begin{array}{l}\text { Non-invasive, does not involve ionizing radiation, and is not affected by } \\
\text { hyperinflation. }\end{array}$ & $\begin{array}{l}\text { Expensive, not widely available and in some } \\
\text { cases claustrophobia can be a problem. }\end{array}$ \\
\hline $\mathrm{RHC}$ & $\begin{array}{l}\text { "Gold standard" } \\
\text { Confirms diagnosis. } \\
\text { Determines severity. } \\
\text { Distinguishes occult LV dysfunction from hyperinflation when PAWP is } \uparrow \text {. } \\
\text { Measures CO and allows calculation of PVR. } \\
\text { Determines responsiveness to } \mathrm{O}_{2} \text {. }\end{array}$ & $\begin{array}{l}\text { Invasive. } \\
\text { Interpretation of pressures may be difficult } \\
\text { when there are large respiratory swings. }\end{array}$ \\
\hline
\end{tabular}

PH: pulmonary hypertension, EKG: electrocardiography, RVH: right ventricular hypertrophy, LAE: left atrial enlargement, LVH: left ventricular hypertrophy, MI: myocardial infarction, CXR: chest X-ray, BNP: brain natriuretic peptide, $\mathrm{PaO}_{2}$ : arterial oxygen tension, eNO: exhaled nitric oxide, NPV: negative predictive value, ECHO: echocardiography, sPAP: systolic pulmonary artery pressure, RV: right ventricular, LVEF: left ventricular ejection fraction, LV: left ventricular, RHC: right heart catheterization, CT: computerized axial tomography, PPV: positive predictive value, MRI: magnetic resonance imaging, CO: cardiac output, PVR: pulmonary vascular resistance, PAWP: pulmonary artery wedge pressure, RAP: right atrial pressure, $\mathrm{O}_{2}$ : oxygen. 
TABLE 4: Various approaches to the treatment of PH in COPD.

\begin{tabular}{lccc}
\hline Counteract hyperinflation & Counteract pulmonary vasoconstriction & Counteract vascular remodeling & Counteract polycythemia \\
\hline Bronchodilators & $\mathrm{O}_{2}$ & $\mathrm{O}_{2}$ & $\mathrm{O}_{2}$ \\
$\mathrm{O}_{2}$ & Pulmonary vasodilators & Pulmonary vasodilators & Phlebotomy \\
Sildenafil & Statins & ARB \\
LVRS (unless $\mathrm{PH}$ severe) & Lung transplantation \\
& Smoking cessation \\
\hline
\end{tabular}

PH: pulmonary hypertension, $\mathrm{O}_{2}$ : oxygen, LVRS: lung volume reduction surgery, ARB: angiotensin receptor blocker.

7.6. BNP. One study of 38 patients with stable COPD, 20 of whom had clinical cor pulmonale, found significant correlation between brain natriuretic peptide (BNP) and ECHOestimated sPAP $(r=0.68, P=0.001)$ [68]. Elevated BNP also correlated with lower $\mathrm{PaO}_{2}$ suggesting that $\mathrm{BNP}$ can also be released in response to hypoxia.

7.7. Exhaled Nitric Oxide. Clini et al. [69] studied 34 consecutive patients with stable COPD and found that patients with $\mathrm{PH}$ (defined as ECHO-estimated sPAP of $>35 \mathrm{~mm} \mathrm{Hg}$ ) showed lower values of exhaled nitric oxide compared to those without $\mathrm{PH}$.

7.8. Cardiac MRI. This imaging technique produces excellent images of the RV and RV wall thickness shows a high correlation with the mean PAP $(r=0.9 ; P<0.001)$ [70]. Moreover, it offers many advantages: it is non-invasive, does not involve radiation, and is not affected by hyperinflation. However, it is expensive, not widely available and in some cases claustrophobia can preclude its use.

7.9. Chest CT Scan. Enlargement of the main pulmonary artery to $\geq 29 \mathrm{~mm}$ in patients with parenchymal lung disease has been shown to have a sensitivity of $84 \%$, specificity of $75 \%$, PPV of $95 \%$, and positive LR of 3.36 for predicting $\mathrm{PH}$ (defined as mPAP $>20 \mathrm{~mm} \mathrm{Hg}$ ) [71].

In another study the ratio of the pulmonary artery to aortic diameter $>1$ was $70 \%$ sensitive and $92 \%$ specific for $\mathrm{PH}$ (defined as mPAP $>20 \mathrm{~mm} \mathrm{Hg}$ ). The PPV was $96 \%$ and the NPV was $52 \%$ [72].

Moreover, an increased left atrial area on chest CT could suggest left heart dysfunction as a possible cause of $\mathrm{PH}$ [73].

7.10. Right Heart Catheterization. RHC remains the "gold standard" for making a diagnosis of $\mathrm{PH}$, accurately determining its severity, and ruling out left heart disease, especially occult LV diastolic dysfunction. An elevated PAWP is not uncommon in severe COPD and does not necessarily imply LV dyfunction [5] as it may be secondary to hyperinflation [21]. Exercise during RHC can help distinguish the cause of an elevated PAWP in COPD. PAWP increases out of proportion to right atrial pressure (RAP) during exercise in comparison to hyperinflation where PAWP and RAP increase proportionately during exercise [74]. Moreover, RHC also measures CO and allows calculation of PVR. Lastly, RHC
TABLE 5: Various pulmonary vasodilators studied for the treatment of $\mathrm{PH}$ in COPD.

\begin{tabular}{|c|c|c|}
\hline \multirow{2}{*}{ Inhaled } & \multicolumn{2}{|c|}{ Systemically delivered } \\
\hline & Nonspecific & Specific \\
\hline $\mathrm{O}_{2}$ & CCB: nifedipine, felodipine & PDE5 I: sildenafil \\
\hline NO & $\alpha-1$ antagonist: prazosin & ETRA: bosentan \\
\hline PG: iloprost & ACEI: captopril & \\
\hline
\end{tabular}

allows determination of responsiveness to $\mathrm{O}_{2}$. However, the invasive nature of the procedure precludes its more widespread use.

\section{Natural History of PH in COPD}

Kessler et al. [75] studied 131 patients with COPD (mean FEV1 $44.6 \pm 15.7 \%$ ) with mild to moderate hypoxemia $\left(\mathrm{PaO}_{2}>60 \mathrm{~mm} \mathrm{Hg}\right)$ and without resting $\mathrm{PH}(\mathrm{mPAP}<$ $20 \mathrm{~mm} \mathrm{Hg}$ ). FEV1 was $<35 \%$ in $28 \%, 35-49 \%$ in $45 \%$, and $\geq 50 \%$ in $26 \%$. Approximately $25 \%$ of the patients developed resting PH during a 6-year followup (mean mPAP $26.8 \pm 6.6 \mathrm{~mm} \mathrm{Hg}$ ). More importantly, twice as many patients with exercising $\mathrm{PH}$ at the onset developed resting $\mathrm{PH}$ over time (32\% versus $16 \%)$. The average change in mPAP was $0.4 \mathrm{~mm} \mathrm{Hg}$ per year. Patients with accelerated worsening of resting mPAP differed by a significant worsening of exercising $\mathrm{mPAP}$ whereas the changes of $\mathrm{FEV} 1$ and $\mathrm{PaO}_{2}$ were rather similar. Moreover, patients who developed resting $\mathrm{PH}$ had higher resting and exercising mPAP and significantly lower resting and exercising $\mathrm{PaO}_{2}$ at baseline [75] .

\section{Treatment of PH Secondary to COPD}

The adverse effect of PH on survival and exercise capacity, and the increased risk of severe acute exacerbations caused by $\mathrm{PH}$ provide the rationale for treating $\mathrm{PH}$ in COPD. The goals of treatment, therefore, are to improve survival, improve exercise tolerance, reduce exacerbations, and improve quality of life. Various approaches to the treatment of PH in COPD are listed in Table 4. Various pulmonary vasodilators used in the treatment of PH in COPD are listed in Table 5. 


\section{Oxygen}

LTOT improves survival in stable COPD patients with resting hypoxemia $\left(\mathrm{PaO}_{2}<55 \mathrm{~mm} \mathrm{Hg}\right)$ and is associated with a mild improvement in pulmonary hemodynamics $[76,77]$.

In the Medical Research Council trial $(N=87)$, mortality rate at 5 years was $67 \%$ in the no- $\mathrm{O}_{2}$ group and $45 \%$ in the $\mathrm{O}_{2}$-treated group $(15 \mathrm{~h} /$ day $)$. In patients alive at 500 days who received repeat $\mathrm{RHC}$, $\mathrm{PPAP}$ increased in the no- $\mathrm{O}_{2}$ group $(n=21)$ at an average rate of $2.7 \mathrm{~mm} \mathrm{Hg} /$ year and remained unchanged in the $\mathrm{O}_{2}$-treated group $(n=21)$ [76]. In the Nocturnal Oxygen Therapy (NOT) Trial $(N=200)$, the mortality rate after 1 year was $11.9 \%$ in the continuous $\mathrm{O}_{2}$ therapy group (averaging $17 \mathrm{~h} /$ day) and $20.6 \%$ in the nocturnal $\mathrm{O}_{2}$ therapy group (averaging $12 \mathrm{~h}$ /day). In patients undergoing hemodynamic measurement at baseline and 6 months after enrollment $(n=117)$, mPAP showed a slight rise in the nocturnal $\mathrm{O}_{2}$ therapy group and a slight fall (at an average of $3 \mathrm{~mm} \mathrm{Hg}$ /year) in the continuous $\mathrm{O}_{2}$ therapy group. PVR decreased by $11.1 \%$ in the continuous $\mathrm{O}_{2}$ therapy group but increased by $6.5 \%$ in the nocturnal $\mathrm{O}_{2}$ therapy group [78].

Unfortunately not all patients with COPD who meet criteria for LTOT benefit from it. Ashutosh et al. [79] showed that patients who exhibited a significant drop in mean PAP of $\geq 5 \mathrm{~mm} \mathrm{Hg}$ after acute $\mathrm{O}_{2}$ therapy ( $28 \%$ for $24 \mathrm{~h}$ ) had an $88 \%$ 2 -year survival compared to $22 \%$ in nonresponders when both groups of patients were subsequently treated with continuous LTOT [79]. Of note, room air $\mathrm{VO}_{2}$ max provided the same information in that study with $6.5 \mathrm{~mL} / \mathrm{kg} / \mathrm{min}$ being the cut-off that distinguished responders from nonresponders [79].

Similarly, even in the landmark NOT trial $\mathrm{O}_{2}$ therapy resulted in an improved survival only in patients whose baseline SVI was $>30 \mathrm{~mL} /$ beat $/ \mathrm{m}^{2}$ (in the continuous $\mathrm{O}_{2}$ group) or PVR was $<400$ dyne $\cdot \mathrm{s} \cdot \mathrm{cm}^{-5}$ (in the nocturnal $\mathrm{O}_{2}$ group) [78].

Weitzenblum et al. who followed up 16 hypoxemic COPD patients on LTOT for a period of 6 years demonstrated a reversal but not normalization of the PAP [15].

Moreover, supplemental $\mathrm{O}_{2}$ during exercise decreases PAP and increases exercise tolerance even in COPD patients with mild resting hypoxemia $\left(\mathrm{PaO}_{2}>60 \mathrm{~mm} \mathrm{Hg}\right)$ and moderate-to-severe airflow obstruction [80]. This effect was found to be the result of inhibition of hypoxic pulmonary vasoconstriction and reduction in air trapping (indicated by the difference in slow and forced vital capacity). Others have also shown that supplemental $\mathrm{O}_{2}$ reduces dynamic hyperinflation and consequently the PAP and PAWP $[20,81]$. Supplemental $\mathrm{O}_{2}$ during exercise also improves RV function [82].

Lastly, $\mathrm{O}_{2}$ therapy abolishes the nocturnal rise in PAP acutely [83] as well as decreases PAP in the long-term in COPD patients with $\mathrm{PH}$ and daytime $\mathrm{PaO}_{2}>60 \mathrm{~mm} \mathrm{Hg}$ who experience nocturnal desaturation [84].

\section{Nonspecific Pulmonary Vasodilators}

Various vasodilators: calcium channel blockers, $\beta 2$-agonists, nitrates, angiotensin converting enzyme inhibitors, and $\alpha 1$-antagonists were studied in the 80 s. Most of them caused a modest decrease in MPAP accompanied by an increase in $\mathrm{CO}$ and a decrease in PVR but they were also associated with systemic hypotension and worsening of ventilationperfusion mismatch that in some cases was not offset by the increase in $\mathrm{CO}$ [85].

\section{Specific Pulmonary Vasodilators}

The recent discovery of endothelial dysfunction resulting in the altered production of mediators of tone and/or proliferation, and consequently pulmonary vasoconstriction and vascular remodeling, provides the rationale for considering specific pulmonary vasodilators that also possess antiproliferative properties.

12.1. Inhaled Nitric Oxide. Inhaled nitric oxide (iNO) is a more potent vasodilator than $\mathrm{O}_{2}$. However, when used alone iNO worsens ventilation-perfusion imbalance. In a randomized controlled trial (RCT) 40 patients with severe COPD (mean FEV1 $1.19 \pm 0.6 \mathrm{~L}$ ) and $\mathrm{PH}(\mathrm{mPAP}>25 \mathrm{~mm} \mathrm{Hg})$ who were receiving LTOT were randomized to pulsed iNO (delivered via a novel device NOXXI; Messer, Austria) plus $\mathrm{O}_{2}$ or $\mathrm{O}_{2}$ alone for 3 months [86]. There was a significant improvement in mPAP, PVR, and CO. The mPAP decreased from 27.6 to $20.6 \mathrm{~mm} \mathrm{Hg}(P<0.001)$; PVR decreased from 276.9 to 173 dyne $\cdot s \cdot \mathrm{cm}^{-5}(P<0.001)$. Systemic hemodynamics and left heart function remained unchanged. $\mathrm{PaCO}_{2}$ decreased significantly in the treatment group, suggesting improved perfusion of the better ventilated areas. Significant methemoglobinemia was not seen. Although this study shows a promising role for iNO in stable COPD patients with $\mathrm{PH}$, it is important to realize that iNO needs to be delivered in a pulsed manner to limit the formation of nitrogen dioxide and to avoid worsening ventilation-perfusion mismatch, and such delivery requires a more practical device.

12.2. Inhaled Iloprost. In a study by Dernaika et al. [87] 10 males with FEV1 < 65\% with $\mathrm{Pa} \mathrm{O}_{2} 60-75 \mathrm{~mm} \mathrm{Hg}$ and $\mathrm{PH}$ (defined as sPAP > $35 \mathrm{~mm} \mathrm{Hg}$ plus RV dilatation and/or RV hypertrophy on ECHO) were evaluated before and after inhaling 2 doses of iloprost $(2.5 \mu \mathrm{g})$. PFT, ABG, 6MWT and ventilatory equivalents for $\mathrm{O}_{2}\left(\mathrm{VE} / \mathrm{VO}_{2}\right)$ and $\mathrm{CO}_{2}$ $\left(\mathrm{VE} / \mathrm{VCO}_{2}\right)$ were performed at baseline, $30 \mathrm{~min}$ following each dose of iloprost, and $2 \mathrm{~h}$ after the second dose. Iloprost was associated with improved ventilation-perfusion matching and exercise tolerance. The 6MWD increased by $49.8 \pm$ $35 \mathrm{~m}(P=0.02)$.

12.3. Lessons Learnt from the Trials of Inhaled Pulmonary Vasodilators. In patients with severe COPD and resting mPAP > $25 \mathrm{~mm} \mathrm{Hg}$ inhaled $\mathrm{NO}$ and $\mathrm{O}_{2}$ improve pulmonary hemodynamics and ventilation-perfusion mismatch. The recent development of a lightweight (approximately $4 \mathrm{~kg}$ ) and portable pulsed delivery system INOpulse DS, that also eliminates the need for calibration or monitoring of $\mathrm{NO}$ or $\mathrm{NO}_{2}$, offers the possibility of using inhaled $\mathrm{NO}$ in COPD patients with $\mathrm{PH}$. However, this promising device has not been studied in COPD or PH. 
In patients with COPD with FEV1 $<65 \%$ and ECHOestimated resting sPAP $>35 \mathrm{~mm} \mathrm{Hg}$ iloprost alone improves ventilation-perfusion mismatch and 6MWD. However, its effects last only 2 hours. Another inhaled prostaglandin treprostinil, which is now available and has a longer duration of action, may be a more feasible option. However, it has not been studied in COPD.

12.4. Sildenafil. Alp et al. [88] were the first to report on the acute and long-term effects of sildenafil in COPD. They showed that in 6 patients with COPD with FEV $1<50 \%$ and PH (mPAP $29.5 \pm 5.2 \mathrm{~mm} \mathrm{Hg}$ ) sildenafil $50 \mathrm{mg}$ IV, once followed by $50 \mathrm{mg}$ PO BID for 3 months, resulted in significant improvement in both hemodynamics and 6MWD. The mean $6 \mathrm{MWD}$ increased by $82 \mathrm{~m}$ (from $351 \pm 49$ to $433 \pm 52 \mathrm{~m}$ ) after 3 months.

However, Holverda et al. [89] failed to show similar results in two studies. They studied the acute effects of a single oral dose of sildenafil $50 \mathrm{mg}$ in 18 patients with GOLD stage II-IV and showed that regardless of the MPAP at rest, sildenafil attenuated the increase in MPAP during submaximal exercise but this was neither accompanied by enhanced $\mathrm{SV}$ and CO, nor by improved exercise capacity. However, only 11 patients had PH: 5 at rest $(\mathrm{mPAP}>25 \mathrm{~mm} \mathrm{Hg}$ ) and 6 with $\mathrm{PH}$ on exercise (mPAP $>30 \mathrm{~mm} \mathrm{Hg}$ ).

The same group went on to study the effects of sildenafil $50 \mathrm{mg}$ PO TID for 3 months in 15 patients with GOLD stage II-IV and reported similar results-neither SV nor exercise capacity improved [90]. However, again, not all patients had PH—only 9 had PH: 5 at rest $(\mathrm{mPAP}>25 \mathrm{~mm} \mathrm{Hg})$ and 4 on exercise (mPAP > $30 \mathrm{~mm} \mathrm{Hg}$ ).

In a randomized dose comparison trial of sildenafil 20 versus $40 \mathrm{mg}$ in 20 patients with COPD and resting $\mathrm{PH}$ (mPAP > $20 \mathrm{~mm} \mathrm{Hg}$ ) both doses improved pulmonary hemodynamics at rest and during exercise but this was accompanied by worsening hypoxemia albeit only at rest [91]. Interestingly, there was also noted to be a slight but statistically significant improvement in FEV1 and forced vital capacity (FVC). Although such a bronchodilatory effect of sildenafil has also been reported in two patients in the literature [92] and is probably mediated through its inhibition of the phosphodiesterase-5 enzyme [93], it has not been evaluated in a controlled manner.

On the other hand, in a double blind RCT of 33 patients with severe COPD and ECHO-estimated sPAP $>40 \mathrm{~mm} \mathrm{Hg}$ Rao et al. [94] showed that the median 6MWD improved by $191 \mathrm{~m}$ and sPAP by $12 \mathrm{~mm} \mathrm{Hg}$ after sildenafil $20 \mathrm{mg}$ PO TID for 3 months $(P<0.05)$.

12.5. Bosentan. In a double blind RCT of 30 patients with severe to very severe COPD Stolz et al. [95] showed that bosentan $125 \mathrm{mg}$ PO BID for 3 months not only failed to improve exercise capacity but also deteriorated hypoxemia and functional status. It is important to keep in mind that only 14 of 20 patients in the bosentan group and 6 of 10 patients in the placebo group had $\mathrm{PH}$ at rest (defined as ECHO-estimated sPAP $>30 \mathrm{~mm} \mathrm{Hg}$ without adding central venous pressure).
On the contrary, in another RCT, this one of 40 patients with COPD and PH $(\mathrm{mPAP}>25 \mathrm{~mm} \mathrm{Hg}$ and PAWP < $15 \mathrm{~mm} \mathrm{Hg}$ ), Valerio et al. [96] showed that bosentan $125 \mathrm{mg}$ PO BID for 18 months resulted in a significant improvement in hemodynamics, 6MWD and BODE index: mPAP from $37 \pm$ to $31 \pm 6 \mathrm{~mm} \mathrm{Hg}$, PVR from $442 \pm 192$ to $392 \pm$ 180 dyne $\cdot \mathrm{s} \cdot \mathrm{cm}^{-5}, 6 \mathrm{MWD}$ from $256 \pm 118$ to $321 \pm 122 \mathrm{~m}$, and BODE index from $6.6 \pm 2.8$ to $5.5 \pm 3$ units. Most patients in stage IV, who made up $30 \%$ of the study population and were characterized by high BODE index, WHO functional class IV, no reversibility with $\mathrm{O} 2$, and higher increases in PAP and PVR during exercise, did not improve but in all such patients the treatment stopped the progressive worsening of hemodynamics.

12.6. Lessons Learnt from the Trials of Oral Specific Pulmonary Vasodilators (Tables 6 and 7). In patients with severe COPD and resting $\mathrm{mPAP}<25 \mathrm{~mm} \mathrm{Hg}$ pulmonary vasodilator therapy may improve PAP during exercise but does not improve SV and CO or exercise capacity. This is probably because hyperinflation plays a predominant role in the pathophysiology of reduced SV and CO in such patients (Figure 3). Severe hyperinflation with inspiratory capacity to total lung capacity (IC/TLC) ratio $<25 \%$ causes a "tamponade" effect on the heart and reduces RV preload $[55,56,97]$ whereas any reduction in RV afterload that may result from pulmonary vasodilatation is of no avail and the SV is limited particularly during exercise. Therefore, pulmonary vasodilators should be neither studied nor used in COPD patients with mild resting $\mathrm{PH}(\mathrm{mPAP}<25 \mathrm{~mm} \mathrm{Hg}$ or ECHO-estimated sPAP $<$ $40 \mathrm{~mm} \mathrm{Hg}$ ) or in COPD patients with PH only on exercise.

On the other hand, in patients with COPD and resting mPAP $>25 \mathrm{~mm} \mathrm{Hg}$ or ECHO-estimated sPAP $>50 \mathrm{~mm} \mathrm{Hg}$ pulmonary vasodilator therapy improves pulmonary hemodynamics and 6MWD. However, more research is needed to recommend the use of pulmonary vasodilators in $\mathrm{PH}$ secondary to COPD. Although COPD patients with severe PH ( $\mathrm{mPAP}>35-45 \mathrm{~mm} \mathrm{Hg}$ ) who probably represent a "vascular phenotype" or have concomitant IPAH will benefit the most from pulmonary vasodilator therapy, it may be worthwhile to try such therapy in COPD patients with less severe $\mathrm{PH}$ (mPAP $25-35 \mathrm{~mm} \mathrm{Hg}$ ) especially if hyperinflation is not playing a significant role. Although it has not been evaluated, pulse oximeter plethysmography waveform analysis to identify "pulsus paradoxus" may be a simpler way of identifying patients with severe hyperinflation with IC/TLC ratio $<25 \%$.

It is important to keep in mind that even specific pulmonary vasodilators can worsen ventilation-perfusion mismatch and hypoxemia at rest that may or may not be offset by an increase in CO. Lastly, lack of acute responsiveness to pulmonary vasodilators indicates a more altered vasculature that may respond to a longer course of therapy or to statins.

\section{Statins}

Statins have anti-inflammatory, antioxidant, and antithrombogenic effects and restore endothelial function [98]. Moreover, statins can reduce the synthesis of ET- 1 at the transcriptional level [99]. 
TABLE 6: Summary of the effects of pulmonary vasodilators in the published studies of such drugs in COPD patients.

\begin{tabular}{|c|c|c|c|c|c|c|c|}
\hline First author & Alp et al. [88] & Holverda et al. [89] & Rietema et al. [90] & Stolz et al. [95] & Valerio et al. [96] & Blanco et al. [91] & Rao et al. [94] \\
\hline Year of publication & 2006 & 2008 & 2008 & 2008 & 2009 & 2010 & 2011 \\
\hline Country & Germany & Netherlands & Netherlands & Switzerland & Italy & Spain & India \\
\hline Drug & Sildenafil & Sildenafil & Sildenafil & Bosentan & Bosentan & Sildenafil & Sildenafil \\
\hline Dose & $50 \mathrm{mg}$ BID & $50 \mathrm{mg}$ & $50 \mathrm{mg}$ TID & $125 \mathrm{mg}$ BID & $125 \mathrm{mg}$ BID & $20 \mathrm{mg}$ vs $40 \mathrm{mg}$ & $20 \mathrm{mg}$ TID \\
\hline Duration & 3 months & Acute effects & 3 months & 3 months & 18 months & Acute effects & 3 months \\
\hline Total $N$ & 5 & 18 & 15 & 20 & 20 & 20 & 17 \\
\hline$N$ with $\mathrm{PH}$ & 5 & 11 & 9 & 14 & 20 & 12 & 17 \\
\hline$N$ with resting $\mathrm{PH}$ & 5 & 5 & 5 & 14 & 20 & 12 & 17 \\
\hline PAP & $\downarrow$ & $\downarrow \mathrm{r}+\mathrm{e}$ & & No $\Delta$ & $\downarrow$ & $\downarrow \mathrm{r}+\mathrm{e}$ & $\downarrow$ \\
\hline $\mathrm{CO}$ & NA & No $\Delta \mathrm{r}+\mathrm{e}$ & No $\Delta \mathrm{r}+\mathrm{e}$ & No $\Delta$ & No $\Delta$ & $\uparrow \mathrm{r}+\mathrm{e}$ & \\
\hline PVR & $\downarrow$ & No $\Delta \mathrm{r}+\mathrm{e}$ & & No $\Delta$ & $\downarrow$ & $\downarrow \mathrm{r}+\mathrm{e}$ & \\
\hline $\mathrm{SpO}_{2} \mathrm{PaO}_{2}$ & & $\downarrow \mathrm{r}+\mathrm{e}$ & No $\Delta \mathrm{r}+\mathrm{e}$ & $\downarrow \mathrm{r}$, No $\Delta \mathrm{e}$ & No $\Delta$ & $\downarrow \mathrm{r}$, No $\Delta \mathrm{e}$ & \\
\hline $\begin{array}{l}6 \mathrm{MWD}(\mathrm{m}) \text { at } \\
\text { baseline }\end{array}$ & $351 \pm 49$ & & $385 \pm 135$ & $339 \pm 81$ & $257 \pm 150$ & $396 \pm 114$ & $269 \pm 140$ \\
\hline $\begin{array}{l}6 \mathrm{MWD}(\mathrm{m}) \text { after } \\
\text { treatment }\end{array}$ & $\uparrow$ to $433 \pm 52$ & & $\uparrow$ to $396 \pm 116$ & $\uparrow$ to $329 \pm 94$ & $\uparrow$ to $321 \pm 122$ & NA & $\uparrow$ by $191 \pm 12$ \\
\hline
\end{tabular}

TABLE 7: Baseline characteristics of the patients who received pulmonary vasodilators in the published studies of such drugs in COPD.

\begin{tabular}{|c|c|c|c|c|c|c|c|}
\hline First author & Alp et al. [88] & Holverda et al. [89] & Rietema et al. [90] & Stolz et al. [95] & Valerio et al. [96] & Blanco et al. [91] & Rao et al. [94] \\
\hline Year of publication & 2006 & 2008 & 2008 & 2008 & 2009 & 2010 & 2011 \\
\hline Drug & Sildenafil & Sildenafil & Sildenafil & Bosentan & Bosentan & Sildenafil & Sildenafil \\
\hline Dose & $50 \mathrm{mg}$ BID & $50 \mathrm{mg}$ & $50 \mathrm{mg}$ TID & $125 \mathrm{mg}$ BID & $125 \mathrm{mg}$ BID & $20 \mathrm{mg}$ vs $40 \mathrm{mg}$ & $20 \mathrm{mg}$ TID \\
\hline Duration & 3 months & Acute effects & 3 months & 3 months & 18 months & Acute effects & 3 months \\
\hline Total $N$ & 5 & 18 & 15 & 20 & 20 & 20 & 17 \\
\hline$N$ with $\mathrm{PH}$ & 5 & 11 & 9 & $14^{\dagger}$ & 20 & 12 & 17 \\
\hline Age (years) & $45-64$ & $66 \pm 9$ & $65 \pm 2$ & $69.5 \pm 8.8$ & $66 \pm 9$ & $64 \pm 7$ & $60 \pm 7$ \\
\hline $\operatorname{sPAP}(\mathrm{mm} \mathrm{Hg})$ & & & & $32^{\ddagger}$ & & & $53 \pm 12$ \\
\hline mPAP (mm Hg) & $29.5 \pm 5.2$ & $23 \pm 10$ & $22 \pm 9$ & & $37 \pm 5$ & $27 \pm 10$ & $33.8 \pm 9.2^{\S}$ \\
\hline $\begin{array}{l}\mathrm{CO}(\mathrm{L} / \mathrm{min}) \\
\mathrm{CJ}\left(\mathrm{L} / \mathrm{min} / \mathrm{m}^{2}\right)\end{array}$ & & $5.5 \pm 1.0$ & $5.4 \pm 1.7$ & $2.45 \pm 0.4$ & $2.8 \pm 0.7$ & $\begin{array}{l}4.9 \pm 0.95 \\
2.7 \pm 0.44\end{array}$ & \\
\hline PVR (dynes.s.cm ${ }^{-5}$ ) & $373 \pm 118$ & $280 \pm 180$ & $259 \pm 166$ & $158 \pm 30$ & $442 \pm 192$ & $339 \pm 165$ & \\
\hline $\mathrm{SpO}_{2}(\%)$ & & $93 \pm 4$ & $95 \pm 2$ & $93 \pm 3$ & & & \\
\hline $\mathrm{PaO}_{2}(\mathrm{~mm} \mathrm{Hg})$ & & & $74 \pm 13$ & & $57 \pm 10$ & $64 \pm 11$ & \\
\hline $\mathrm{PaCO}_{2}(\mathrm{~mm} \mathrm{Hg})$ & & & $39 \pm 6$ & & $46 \pm 8$ & $38.4 \pm 4.5$ & \\
\hline 6MWD (meters) & $351 \pm 49$ & & $385 \pm 135$ & $339 \pm 81$ & $257 \pm 150$ & $396 \pm 114$ & $269 \pm 140$ \\
\hline
\end{tabular}

mg: milligrams, BID: twice a day, TID: three times a day, vs: versus, $N$ : total number of patients who received the study drug, $N$ with PH: number of patients with pulmonary hypertension, PH: pulmonary hypertension, sPAP: systolic pulmonary artery pressure estimated by echocardiography, mPAP: mean pulmonary artery pressure measured by right heart catheterization, CO: cardiac output, CI: cardiac index, PVR: pulmonary vascular resistance, FEV1: forced expiratory volume in the first second, TLC: total lung capacity, DLCO: diffusing capacity for carbon monoxide, $\mathrm{SpO}_{2}$ : oxygen saturation by pulse oximetry, $\mathrm{PaO}_{2}$ : arterial oxygen tension, $\mathrm{PaCO}_{2}$ : arterial carbon dioxide tension, 6MWD: six-minute walk distance.

* resting PH defined as mPAP $>25 \mathrm{~mm} \mathrm{Hg}$ or ECHO estimated sPAP $>40 \mathrm{~mm} \mathrm{Hg}$ unless specified otherwise—see below:

${ }^{\dagger} \mathrm{PH}$ was defined as estimated $\mathrm{sPAP}>30 \mathrm{~mm} \mathrm{Hg}$ without adding central venous pressure (CVP).

${ }^{\ddagger}$ Estimated sPAP without adding CVP. If CVP is assumed to be $5 \mathrm{~mm} \mathrm{Hg}$, this gives a sPAP of $37 \mathrm{~mm} \mathrm{Hg}$ which amounts to a mPAP of $24 \mathrm{~mm} \mathrm{Hg}$ based on the prediction equation $0.6 \times \mathrm{sPAP}+2=\mathrm{mPAP}[113]$.

$\S$ Calculated mPAP based on the prediction equation $0.6 \times \mathrm{sPAP}+2=\operatorname{mPAP}[113]$. 


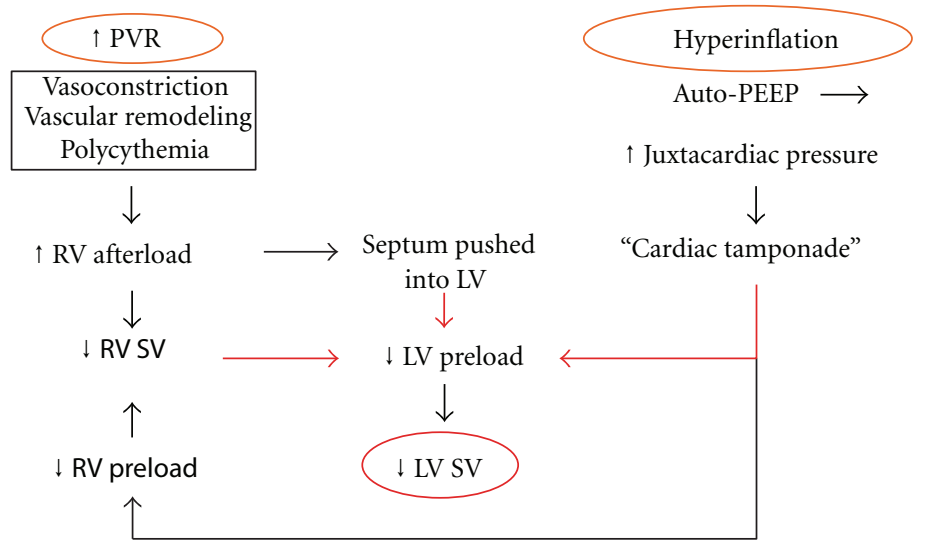

FIGURE 3: Pathophysiology of reduced SV in COPD. SV: stroke volume, PVR: pulmonary vascular resistance, RV: right ventricular, LV: left ventricular, PEEP: positive end-expiratory pressure.

In a double-blind parallel design study [100], 53 patients with COPD and ECHO-estimated sPAP > $35 \mathrm{~mm} \mathrm{Hg}$ were randomly assigned to receive either pravastatin $40 \mathrm{mg}$ daily or placebo for 6 months. Exercise time increased significantly $52 \%$ from $660 \pm 352$ to $1006 \pm 316$ seconds $(P<0.0001)$ in the treatment group. ECHO-estimated sPAP decreased significantly from $47 \pm 8$ to $40 \pm 6 \mathrm{~mm} \mathrm{Hg}$. There was also significant improvement in Borg dyspnea score.

In an animal study, Wright et al. [101] studied the effects of simvastatin in guinea pigs exposed to cigarette smoke for 6 months. In half of the animals simvastatin was introduced after 3 months. Cigarette smoke increased the sPAP after approximately 4 weeks. Simvastatin returned the pressure to control levels within 4 weeks of starting treatment, and ameliorated smoke-induced small arterial remodeling as well as emphysema measured both physiologically and morphometrically at 6 months, but did not prevent smokeinduced small airway remodeling either physiologically or morphologically. In precision-cut lung slices simvastatin reversed small arterial endothelial dysfunction and partially reversed smoke-induced loss of vascular NO generation.

Both studies show prospects for the use of statins in COPD and warrant more research.

\section{Diuretics}

Diuretics reduce right ventricular dilatation and improve its contractility and also reduce extravascular lung water [102]. They should be used cautiously as they can cause intravascular volume depletion that may deprive the RV of adequate preload to maintain a normal SV.

\section{Phlebotomy}

Phlebotomy is usually indicated in patients with polycythemia not responding to LTOT. In a small study of 7 patients with stable severe COPD (FEV1 $33 \pm 3 \%$ of predicted) and $\mathrm{PH}$, Borst et al. [103] showed that isovolemic phlebotomy resulted in improvement in pulmonary hemodynamics, gas exchange, and exercise tolerance. The patients were phlebotomized 5-6 times over a period of 3 months with substitution of $6 \%$ hydroxyethyl starch (molecular weight $40,000)$. This resulted in a stepwise reduction of the hematocrit from $53.3 \pm 2.6$ to $45.8 \pm 3.1 \%$. Mean PAP decreased from $30 \pm 3$ to $22 \pm 2 \mathrm{~mm} \mathrm{Hg}$ and $\mathrm{PaO}_{2}$ increased from $63.2 \pm$ 2.2 to $71.8 \pm 3.7 \mathrm{~mm} \mathrm{Hg}$ at rest. During peak exercise, mPAP decreased from $59 \pm 7$ to $53 \pm 7 \mathrm{~mm} \mathrm{Hg}$ and $\mathrm{PaO}_{2}$ increased from $54.0 \pm 5.7$ to $63.2 \pm 2.4 \mathrm{~mm} \mathrm{Hg}$ after hemodilution. Peak oxygen consumption rose from $573 \pm 84$ to $750 \pm$ $59 \mathrm{~mL} / \mathrm{min}$, corresponding to an increase in CI from $4.25 \pm$ 0.5 to $5.88 \pm 0.76$ liters $/ \mathrm{min} / \mathrm{m}^{2}$. PVR fell from $345 \pm 53$ to $194 \pm 32$ dyne $\cdot \mathrm{s} \cdot \mathrm{cm}^{-5}$. The patients' peak exercise capacity increased from $9.2 \pm 2.0$ before to $13.5 \pm 3.2 \mathrm{~kJ}$ at the end of the study $(P<0.05$ for all differences $)$.

\section{6. “Bloodless Phlebotomy"}

Activation of the renin-angiotensin system may contribute to polycythemia in COPD [104]. Plasma renin and aldosterone levels are increased in such patients when matched with controls for hypoxemia. The mechanism of action is serum-erythropoietin-independent. In a small study, the angiotensin receptor blocker (ARB) losartan was used in weekly escalating doses to a maximum of $100 \mathrm{mg}$ daily for 4 weeks in 9 stable severe COPD patients with polycythemia (hematocrit $>52 \%$ ). The regimen caused a significant reduction in the hematocrit of all patients from $56 \pm 0.9 \%$ to $46 \pm 0.7 \%(P<0.001)$. The higher the baseline value, the greater the reduction in hematocrit $(r=0.7085 ; P<0.05)$ [105]. At 3 months after discontinuation of losartan the hematocrit increased to $50 \pm 0.7 \%$. Similarly, in an RCT of 60 patients with severe COPD another ARB irbesartan also induced a significant reduction in hematocrit [106]. Of note, however, neither study evaluated pulmonary hemodynamics, gas exchange or exercise tolerance which makes it difficult to draw any meaningful conclusions.

Although it is tempting to speculate that such a "bloodless" phlebotomy may also result in improvement in pulmonary hemodynamics, gas exchange, and exercise tolerance, it is important to realize that ARBs are also 
non-specific vasodilators that can cause a modest decrease in mPAP as well as worsen $\mathrm{PaO}_{2}$. In fact in a double-blind RCT of COPD patients with transtricuspid pressure gradient (TTPG) $>30 \mathrm{~mm} \mathrm{Hg}$ more patients in the losartan group $(50 \%)$ than in the placebo group $(22 \%)$ showed a clinically meaningful reduction in TTPG at any time point during the 12-month period, and these effects seemed more marked in patients with higher baseline TTPG. There were no clear improvements in exercise capacity or symptoms, though [107].

\section{Lung Volume Reduction Surgery (LVRS)}

Although lung volume reduction surgery (LVRS) is contraindicated in COPD patients with severe $\mathrm{PH}$ (mPAP > $35 \mathrm{~mm} \mathrm{Hg}$ ), the reduction in hyperinflation and improvement in gas exchange resulting from such surgery are expected to result in an improvement in PAP in patients with less severe $\mathrm{PH}$. On the other hand excision of some viable pulmonary vascular bed may have the adverse effect of worsening PVR. In fact the few studies of pulmonary hemodynamics before and after LVRS have shown that the MPAP remains unchanged after such surgery [108-111]. Earlier and smaller studies showed that mPAP remains unchanged because CO improves when PVR falls after LVRS [108-110]. In contrast, the most recent and largest study of pulmonary hemodynamics before and after LVRS, which was a cardiac substudy of the national emphysema treatment (NET) trial, did not show any significant change in CO [111]. Reasons for the discrepancy between the results of the earlier studies and the NET trial are not clear, but could be due to differences in patient selection, or surgical methods. Moreover, unlike the other studies, the NET trial did not evaluate pulmonary hemodynamics during exercise.

\section{Lung Transplantation}

$\mathrm{PH}$ secondary to COPD is an indication for lung transplantation. Bjortuft et al. [112] investigated a group of 24 patients, including 19 with COPD, who underwent single lung transplantation. The majority (15 out of 24 ) of patients had mildto-moderate $\mathrm{PH}$ at the onset and in these patients mPAP significantly decreased from $28 \pm 1$ to $18 \pm 1 \mathrm{~mm} \mathrm{Hg}$ after transplantation; there was a similar decrease in PVR. These results were maintained after 2 yrs of followup. Therefore, COPD patients with $\mathrm{PH}$ normalize pulmonary haemodynamics after single lung transplantation.

\section{Conclusion}

The pathophysiology of PH in COPD is complex. A diagnosis of $\mathrm{PH}$ in COPD should prompt a search for other causes of $\mathrm{PH}$, particularly left heart dysfunction, OSA, and PE before attributing the $\mathrm{PH}$ to COPD. $\mathrm{PH}$ in COPD adversely affects survival and exercise capacity and is associated with an increased risk of severe acute exacerbations. Unfortunately not all patients with COPD who meet criteria for LTOT benefit from it. Even in those who benefit from LTOT, such therapy may reverse PAP but cannot normalize it.
Moreover, the recent discovery of the key roles of endothelial dysfunction and inflammation in the pathogenesis of $\mathrm{PH}$ provides the rationale for considering specific pulmonary vasodilators that also possess antiproliferative properties and statins. Studies of pulmonary vasodilators and statins for $\mathrm{PH}$ secondary to COPD appear to show a promising role for such therapy in patients with more than mild $\mathrm{PH}$ ( $\mathrm{mPAP}>25 \mathrm{~mm} \mathrm{Hg}$ ) and warrant more research. Success of pulmonary vasodilator therapy appears to depend upon the degree of $\mathrm{PH}$ and the severity of hyperinflation. Such therapy is more likely to be successful when $\mathrm{PH}$ is moderate to severe ( $\mathrm{mPAP}>25 \mathrm{~mm} \mathrm{Hg}$ ) and hyperinflation is not playing a significant role, that is, IC/TLC is $>25 \%$. Although stable COPD patients with severe $\mathrm{PH}(\mathrm{mPAP}>35-45 \mathrm{~mm} \mathrm{Hg}$ ) who probably represent a "vascular phenotype" or have concomitant IPAH warrant pulmonary vasodilator therapy, it may be worthwhile to try such therapy in stable COPD patients with less severe PH ( $\mathrm{mPAP} 25-35 \mathrm{~mm} \mathrm{Hg}$ ) especially if hyperinflation is not severe. On the other hand such therapy should be avoided when $\mathrm{PH}$ is mild or only during exercise or hyperinflation is playing a significant role, that is, IC/TLC is $<25 \%$. Future studies of pharmacotherapy should focus on patients with $\mathrm{PH}$ with $\mathrm{mPAP}>25 \mathrm{~mm} \mathrm{Hg}$ and IC/TLC > 25\%.

\section{References}

[1] G. Simonneau, I. M. Robbins, M. Beghetti et al., "Updated clinical classification of pulmonary hypertension," Journal of the American College of Cardiology, vol. 54, no. 1, pp. S43S54, 2009.

[2] B. Burrows, L. J. Kettel, A. H. Niden, M. Rabinowitz, and C. F. Diener, "Patterns of cardiovascular dysfunction in chronic obstructive lung disease," The New England Journal of Medicine, vol. 286, no. 17, pp. 912-918, 1972.

[3] E. Weitzenblum, A. Sautegeau, and M. Ehrhart, "Long-term course of pulmonary arterial pressure in chronic obstructive pulmonary disease," The American Review of Respiratory Disease, vol. 130, no. 6, pp. 993-998, 1984.

[4] M. Oswald-Mammosser, M. Apprill, P. Bachez, M. Ehrhart, and E. Weitzenblum, "Pulmonary hemodynamics in chronic obstructive pulmonary disease of the emphysematous type," Respiration, vol. 58, no. 5-6, pp. 304-310, 1991.

[5] S. M. Scharf, M. Iqbal, C. Keller et al., "Hemodynamic characterization of patients with severe emphysema," American Journal of Respiratory and Critical Care Medicine, vol. 166, pp. 314-322, 2002.

[6] G. Thabut, G. Dauriat, J. B. Stern et al., "Pulmonary hemodynamics in advanced COPD candidates for lung volume reduction surgery or lung transplantation," Chest, vol. 127, no. 5, pp. 1531-1536, 2005.

[7] M. J. Cuttica, R. Kalhan, O. A. Shlobin et al., "Categorization and impact of pulmonary hypertension in patients with advanced COPD," Respiratory Medicine, vol. 104, no. 12, pp. 1877-1882, 2010.

[8] E. Weitzenblum, "Chronic cor pulmonale," Heart, vol. 89, no. 2, pp. 225-230, 2003.

[9] J. R. Catterall, N. J. Douglas, and P. M. A. Calverley, "Transient hypoxemia during sleep in chronic obstructive pulmonary disease is not a sleep apnea syndrome," The American Review of Respiratory Disease, vol. 128, no. 1, pp. 24-29, 1983. 
[10] E. C. Fletcher and D. C. Levin, "Cardiopulmonary hemodynamics during sleep in subjects with chronic obstructive pulmonary disease. The effect of short- and long-term oxygen," Chest, vol. 85, no. 1, pp. 6-14, 1984.

[11] G. Coccagna and E. Lugaresi, "Arterial blood gases and pulmonary and systemic arterial pressure during sleep in chronic obstructive pulmonary disease," Sleep, vol. 1, no. 2, pp. 117-124, 1978.

[12] A. S. Abraham, R. B. Cole, I. D. Green, R. B. HedworthWhitty, S. W. Clarke, and J. M. Bishop, "Factors contributing to the reversible pulmonary hypertension of patients with acute respiratory failure studies by serial observations during recovery," Circulation Research, vol. 24, no. 1, pp. 51-60, 1969.

[13] E. Weitzenblum, A. Loiseau, C. Hirth, R. Mirhom, and J. Rasaholinjanahary, "Course of pulmonary hemodynamics in patients with chronic obstructive pulmonary disease," Chest, vol. 75, no. 6, pp. 656-662, 1979.

[14] M. Oswald-Mammosser, E. Weitzenblum, E. Quoix et al., "Prognostic factors in COPD patients receiving long-term oxygen therapy: importance of pulmonary artery pressure," Chest, vol. 107, no. 5, pp. 1193-1198, 1995.

[15] E. Weitzenblum, A. Sautegeau, M. Ehrhart, M. Mammosser, and A. Pelletier, "Long-term oxygen therapy can reverse the progression of pulmonary hypertension in patients with chronic obstructive pulmonary disease," The American Review of Respiratory Disease, vol. 131, no. 4, pp. 493-498, 1985.

[16] J. Zieliński, M. Tobiasz, I. Hawryłkiewicz, P. Śliwiński, and G. Pałasiewicz, "Effects of long-term oxygen therapy on pulmonary hemodynamics in COPD patients: a 6-year prospective study," Chest, vol. 113, no. 1, pp. 65-70, 1998.

[17] M. W. Sims, D. J. Margolis, A. R. Localio, R. A. Panettieri, S. M. Kawut, and J. D. Christie, "Impact of pulmonary artery pressure on exercise function in severe COPD," Chest, vol. 136, no. 2, pp. 412-419, 2009.

[18] R. Kessler, M. Faller, G. Fourgaut, B. Mennecier, and E. Weitzenblum, "Predictive factors of hospitalization for acute exacerbation in a series of 64 patients with chronic obstructive pulmonary disease," American Journal of Respiratory and Critical Care Medicine, vol. 159, no. 1, pp. 158-164, 1999.

[19] K. Kubo, R. L. Ge, T. Koizumi et al., "Pulmonary artery remodeling modifies pulmonary hypertension during exercise in severe emphysema," Respiration Physiology, vol. 120, no. 1, pp. 71-79, 2000.

[20] J. L. Wright, L. Lawson, P. D. Pare et al., "The structure and function of the pulmonary vasculature in mild chronic obstructive pulmonary disease. The effect of oxygen and exercise," The American Review of Respiratory Disease, vol. 128, no. 4, pp. 702-707, 1983.

[21] J. Butler, F. Schrijen, A. Henriquez, J. M. Polu, and R. K. Albert, "Cause of the raised wedge pressure on exercise in chronic obstructive pulmonary disease," The American Review of Respiratory Disease, vol. 138, no. 2, pp. 350-354, 1988.

[22] J. A. Barberà and I. Blanco, "Pulmonary hypertension in patients with chronic obstructive pulmonary disease: advances in pathophysiology and management," Drugs, vol. 69, no. 9, pp. 1153-1171, 2009.

[23] C. A. Hales, "The site and mechanism of oxygen sensing for the pulmonary vessels," Chest, vol. 88, no. 4, pp. 235S-240S, 1985.

[24] U. Von Euler and G. Liljerstrand, "Observations on the pulmonary arterial blood pressure in the cat," Acta Physiologica Scandinavica, vol. 12, pp. 301-320, 1946.
[25] K. R. Stenmark, K. A. Fagan, and M. G. Frid, "Hypoxiainduced pulmonary vascular remodeling: cellular and molecular mechanisms," Circulation Research, vol. 99, no. 7, pp. 675-691, 2006.

[26] M. Wilkinson, C. A. Langhorne, D. Heath, G. R. Barer, and P. Howard, "A pathophysiological study of 10 cases of hypoxic cor pulmonale," Quarterly Journal of Medicine, vol. 66, no. 249, pp. 65-85, 1988.

[27] F. Magee, J. L. Wright, B. R. Wiggs, P. D. Pare, and J. C. Hogg, "Pulmonary vascular structure and function in chronic obstructive pulmonary disease," Thorax, vol. 43, no. 3, pp. 183189, 1988.

[28] J. L. Wright, T. Petty, and W. M. Thurlbeck, "Analysis of the structure of the muscular pulmonary arteries in patients with pulmonary hypertension and COPD: national Institutes of Health nocturnal oxygen therapy trial," Lung, vol. 170, no. 2, pp. 109-124, 1992.

[29] S. Santos, V. I. Peinado, J. Ramírez et al., "Characterization of pulmonary vascular remodelling in smokers and patients with mild COPD," European Respiratory Journal, vol. 19, no. 4, pp. 632-638, 2002.

[30] G. G. Pietra, F. Capron, S. Stewart et al., "Pathologic assessment of vasculopathies in pulmonary hypertension," Journal of the American College of Cardiology, vol. 43, no. 12, pp. S25S32, 2004.

[31] A. T. Dinh-Xuan, T. W. Higenbottam, C. A. Clelland et al., "Impairment of endothelium-dependent pulmonary-artery relaxation in chronic obstructive lung disease," The New England Journal of Medicine, vol. 324, no. 22, pp. 1539-1547, 1991.

[32] J. D. Lee, L. Taraseviciene-Stewart, R. Keith, M. W. Geraci, and N. F. Voelkel, "The expression of prostacyclin synthase is decreased in the small pulmonary arteries from patients with emphysema," Chest, vol. 128, no. 6, p. 575S, 2005.

[33] A. Giaid, M. Yanagisawa, D. Langleben et al., "Expression of endothelin-1 in the lungs of patients with pulmonary hypertension," The New England Journal of Medicine, vol. 328, no. 24, pp. 1732-1739, 1993.

[34] K. Spiropoulos, G. Trakada, E. Nikolaou et al., "Endothelin1 levels in the pathophysiology of chronic obstructive pulmonary disease and bronchial asthma," Respiratory Medicine, vol. 97, no. 8, pp. 983-989, 2003.

[35] V. I. Peinado, J. A. Barberà, P. Abate et al., "Inflammatory reaction in pulmonary muscular arteries of patients with mild chronic obstructive pulmonary disease," American Journal of Respiratory and Critical Care Medicine, vol. 159, no. 5, part 1, pp. 1605-1611, 1999.

[36] R. E. Walter, J. B. Wilk, M. G. Larson et al., "Systemic inflammation and COPD: the Framingham heart study," Chest, vol. 133, no. 1, pp. 19-25, 2008.

[37] W. Q. Gan, S. F. P. Man, A. Senthilselvan, and D. D. Sin, "Association between chronic obstructive pulmonary disease and systemic inflammation: a systematic review and a metaanalysis," Thorax, vol. 59, no. 7, pp. 574-580, 2004.

[38] A. Chaouat, L. Savale, C. Chouaid et al., "Role for interleukin-6 in COPD-related pulmonary hypertension," Chest, vol. 136, no. 3, pp. 678-687, 2009.

[39] Y. S. Kwon, S. Y. Chi, H. J. Shin et al., "Plasma C-Reactive protein and Endothelin-1 level in patients with chronic obstructive pulmonary disease and pulmonary hypertension," Journal of Korean Medical Science, vol. 25, no. 10, pp. 14871491, 2010.

[40] C. Alessandri, S. Basili, F. Violi et al., "Hypercoagulability state in patients with chronic obstructive pulmonary disease," 
Thrombosis and Haemostasis, vol. 72, no. 3, pp. 343-346, 1994.

[41] M. Erelel, C. Cuhadaroglu, T. Ece, and O. Arseven, "The frequency of deep venous thrombosis and pulmonary embolus in acute exacerbation of chronic obstructive pulmonary disease," Respiratory Medicine, vol. 96, no. 7, pp. 515-518, 2002.

[42] J. Rizkallah, S. F. P. Man, and D. D. Sin, "Prevalence of pulmonary embolism in acute exacerbations of COPD: a systematic review and meta-analysis," Chest, vol. 135, pp. 786-793, 2009.

[43] F. Fraisse, L. Holzapfel, J. M. Couland et al., "Nadroparin in the prevention of deep vein thrombosis in acute decompensated COPD. The association of non-university affiliated intensive care specialist physicians of France," American Journal of Respiratory and Critical Care Medicine, vol. 161, no. 4, part 1, pp. 1109-1114, 2000.

[44] C. A. Keller, K. S. Naunheim, J. Osterloh, J. Espiritu, J. W. McDonald, and R. R. Ramos, "Histopathologic diagnosis made in lung tissue resected from patients with severe emphysema undergoing lung volume reduction surgery," Chest, vol. 111, no. 4, pp. 941-947, 1997.

[45] A. Nakamura, N. Kasamatsu, I. Hashizume et al., "Effects of hemoglobin on pulmonary arterial pressure and pulmonary vascular resistance in patients with chronic emphysema," Respiration, vol. 67, no. 5, pp. 502-506, 2000.

[46] S. Deem, E. R. Swenson, M. K. Alberts, R. G. Hedges, and M. J. Bishop, "Red-blood-cell augmentation of hypoxic pulmonary vasoconstriction: hematocrit dependence and the importance of nitric oxide," American Journal of Respiratory and Critical Care Medicine, vol. 157, no. 4, pp. 1181-1186, 1998.

[47] I. Azarov, K. T. Huang, S. Basu, M. T. Gladwin, N. Hogg, and D. B. Kim-Shapiro, "Nitric oxide scavenging by red blood cells as a function of hematocrit and oxygenation," Journal of Biological Chemistry, vol. 280, no. 47, pp. 39024-39032, 2005.

[48] S. Eddahibi, A. Chaouat, N. Morrell et al., "Polymorphism of the serotonin transporter gene and pulmonary hypertension in chronic obstructive pulmonary disease," Circulation, vol. 108, no. 15, pp. 1839-1844, 2003.

[49] S. J. King, F. M. Booyse, P. H. Lin, M. Traylor, A. J. Narkates, and S. Oparil, "Hypoxia stimulates endothelial cell angiotensin-converting enzyme antigen synthesis," American Journal of Physiology, vol. 256, no. 6, pp. C1231-C1238, 1989.

[50] H. Kanazawa, T. Okamoto, K. Hirata, and J. Yoshikawa, "Deletion polymorphisms in the angiotensin converting enzyme gene are associated with pulmonary hypertension evoked by exercise challenge in patients with chronic obstructive pulmonary disease," American Journal of Respiratory and Critical Care Medicine, vol. 162, no. 4, pp. 1235-1238, 2000.

[51] E. M. Tschernko, E. M. Gruber, P. Jaksch et al., "Ventilatory mechanics and gas exchange during exercise before and after lung volume reduction surgery," American Journal of Respiratory and Critical Care Medicine, vol. 158, no. 5, pp. 14241431, 1998.

[52] W. MacNee, "Right heart function in COPD," Seminars in Respiratory and Critical Care Medicine, vol. 31, no. 3, pp. 295$312,2010$.

[53] S. J. Dong, A. P. Crawley, J. H. MacGregor et al., "Regional left ventricular systolic function in relation to the cavity geometry in patients with chronic right ventricular pressure overload: a three-dimensional tagged magnetic resonance imaging study," Circulation, vol. 91, no. 9, pp. 2359-2370, 1995.
[54] A. Vonk Noordegraaf, J. T. Marcus, B. Roseboom, P. E. Postmus, T. J. Faes, and P. M. de Vries, "The effect of right ventricular hypertrophy on left ventricular ejection fraction in pulmonary emphysema," Chest, vol. 112, no. 3, pp. 640645, 1997.

[55] C. Vassaux, L. Torre-Bouscoulet, S. Zeineldine et al., "Effects of hyperinflation on the oxygen pulse as a marker of cardiac performance in COPD," European Respiratory Journal, vol. 32, no. 5, pp. 1275-1282, 2008.

[56] H. Watz, B. Waschki, T. Meyer et al., "Decreasing cardiac chamber sizes and associated heart dysfunction in COPD: role of hyperinflation," Chest, vol. 138, no. 1, pp. 32-38, 2010.

[57] W. MacNee, C. G. Wathen, D. C. Flenley, and A. D. Muir, "The effects of controlled oxygen therapy on ventricular function in patients with stable and decompensated cor pulmonale," The American Review of Respiratory Disease, vol. 137, no. 6, pp. 1289-1295, 1988.

[58] E. Weitzenblum, M. Apprill, M. Oswald-Mammosser, A. Chaouat, and J. L. Imbs, "Pulmonary hemodynamics in patients with chronic obstructive pulmonary disease before and during an episode of peripheral edema," Chest, vol. 105, no. 5, pp. 1377-1382, 1994.

[59] K. M. Skwarski, D. Morrison, A. Barratt, M. Lee, and W. Macnee, "Effects of hypoxia on renal hormonal balance in normal subjects and in patients with COPD," Respiratory Medicine, vol. 92, no. 12, pp. 1331-1336, 1998.

[60] P. W. De Leeuw and A. Dees, "Fluid homeostasis in chronic obstructive lung disease," European Respiratory Journal, vol. 22, supplement 46, pp. 33S-40S, 2003.

[61] T. Bratel, S. Ljungman, M. Runold, and P. Stenvinkel, "Renal function in hypoxaemic chronic obstructive pulmonary disease: effects of long-term oxygen treatment," Respiratory Medicine, vol. 97, no. 4, pp. 308-316, 2003.

[62] A. Chaouat, A. S. Bugnet, N. Kadaoui et al., "Severe pulmonary hypertension and chronic obstructive pulmonary disease," American Journal of Respiratory and Critical Care Medicine, vol. 172, no. 2, pp. 189-194, 2005.

[63] S. Holverda, H. J. Bogaard, H. Groepenhoff, P. E. Postmus, A. Boonstra, and A. Vonk-Noordegraaf, "Cardiopulmonary exercise test characteristics in patients with chronic obstructive pulmonary disease and associated pulmonary hypertension," Respiration, vol. 76, no. 2, pp. 160-167, 2008.

[64] R. A. Matthay, M. I. Schwarz, J. H. Ellis Jr. et al., "Pulmonary artery hypertension in chronic obstructive pulmonary disease: determination by chest radiography," Investigative Radiology, vol. 16, no. 2, pp. 95-100, 1981.

[65] R. A. Incalzi, L. Fuso, M. De Rosa et al., "Electrocardiographic signs of chronic cor pulmonale: a negative prognostic finding in chronic obstructive pulmonary disease," Circulation, vol. 99, no. 12, pp. 1600-1605, 1999.

[66] S. M. Arcasoy, J. D. Christie, V. A. Ferrari et al., "Echocardiographic assessment of pulmonary hypertension in patients with advanced lung disease," American Journal of Respiratory and Critical Care Medicine, vol. 167, no. 5, pp. 735-740, 2003.

[67] W. Matsuyama, R. Ohkubo, K. Michizono et al., "Usefulness of transcutaneous Doppler jugular venous echo to predict pulmonary hypertension in COPD patients," European Respiratory Journal, vol. 17, no. 6, pp. 1128-1131, 2001.

[68] E. Bozkanat, E. Tozkoparan, O. Baysan, O. Deniz, F. Ciftci, and M. Yokusoglu, "The significance of elevated brain natriuretic peptide levels in chronic obstructive pulmonary disease," Journal of International Medical Research, vol. 33, no. 5, pp. 537-544, 2005. 
[69] E. Clini, G. Cremona, M. Campana et al., "Production of endogenous nitric oxide in chronic obstructive pulmonary disease and patients with cor pulmonale: correlates with echo-doppler assessment," American Journal of Respiratory and Critical Care Medicine, vol. 162, no. 2, part 1, pp. 446450, 2000.

[70] H. Saito, T. Dambara, M. Aiba, T. Suzuki, and S. Kira, "Evaluation of cor pulmonale on a modified short-axis section of the heart by magnetic resonance imaging," The American Review of Respiratory Disease, vol. 146, no. 6, pp. 1576-1581, 1992.

[71] R. T. Tan, R. Kuzo, L. R. Goodman, R. Siegel, G. B. Haasler, and K. W. Presberg, "Utility of CT scan evaluation for predicting pulmonary hypertension in patients with parenchymal lung disease," Chest, vol. 113, no. 5, pp. 1250-1256, 1998.

[72] C. S. Ng, A. U. Wells, and S. P. G. Padley, "A CT sign of chronic pulmonary arterial hypertension: the ratio of main pulmonary artery to aortic diameter," Journal of Thoracic Imaging, vol. 14, no. 4, pp. 270-278, 1999.

[73] Z. Safdar, M. F. Katz, and A. E. Frost, "Computed axial tomography evidence of left atrial enlargement: a predictor of elevated pulmonary capillary wedge pressure in pulmonary hypertension," International Journal of General Medicine, vol. 3, pp. 23-29, 2010.

[74] F. Chabot, F. Schrijen, F. Poincelot, and J. M. Polu, "Interpretation of high wedge pressure on exercise in patients with chronic obstructive pulmonary disease," Cardiology, vol. 95, no. 3, pp. 139-145, 2001.

[75] R. Kessler, M. Faller, E. Weitzenblum et al., "'Natural history' of pulmonary hypertension in a series of 131 patients with chronic obstructive lung disease," American Journal of Respiratory and Critical Care Medicine, vol. 164, no. 2, pp. 219-224, 2001.

[76] C. Stuart-Harris, J. M. Bishop, T. J. H. Clark et al., "Long term domiciliary oxygen therapy in chronic hypoxic cor pulmonale complicating chronic bronchitis and emphysema," The Lancet, vol. 1, no. 8222, pp. 681-686, 1981.

[77] P. A. Kvale, W. A. Conway, E. O. Coates Jr. et al., "Continuous or nocturnal oxygen therapy in hypoxemic chronic obstructive lung disease. A clinical trial," Annals of Internal Medicine, vol. 93, no. 3, pp. 391-398, 1980.

[78] R. M. Timms, F. U. Khaja, and G. W. Williams, "Hemodynamic response to oxygen therapy in chronic obstructive pulmonary disease," Annals of Internal Medicine, vol. 102, no. 1, pp. 29-36, 1985.

[79] K. Ashutosh, G. Mead, and M. Dunsky, "Early effects of oxygen administration and prognosis in chronic obstructive pulmonary disease and cor pulmonale," The American Review of Respiratory Disease, vol. 127, no. 4, pp. 399-404, 1983.

[80] K. Fujimoto, Y. Matsuzawa, S. Yamaguchi, T. Koizumi, and K. Kubo, "Benefits of oxygen on exercise performance and pulmonary hemodynamics in patients with COPD with mild hypoxemia," Chest, vol. 122, no. 2, pp. 457-463, 2002.

[81] A. Somfay, J. Porszasz, S. M. Lee, and R. Casaburi, "Doseresponse effect of oxygen on hyperinflation and exercise endurance in nonhypoxaemic COPD patients," European Respiratory Journal, vol. 18, no. 1, pp. 77-84, 2001.

[82] S. K. Olvey, L. A. Reduto, and P. M. Stevens, "First pass radionuclide assessment of right and left ventricular ejection fraction in chronic pulmonary disease. Effect of oxygen upon exercise response," Chest, vol. 78, no. 1, pp. 4-9, 1980.

[83] D. A. Raeside, A. Brown, K. R. Patel, D. Welsh, and A. J. Peacock, "Ambulatory pulmonary artery pressure monitoring during sleep and exercise in normal individuals and patients with COPD," Thorax, vol. 57, no. 12, pp. 1050-1053, 2002.

[84] E. C. Fletcher, R. A. Luckett, S. Goodnight-White, C. C. Miller, W. Qian, and C. Costarangos-Galarza, "A doubleblind trial of nocturnal supplemental oxygen for sleep desaturation in patients with chronic obstructive pulmonary disease and a daytime $\mathrm{PA}_{\mathrm{O}_{2}}$ above $60 \mathrm{~mm} \mathrm{Hg}$," The American Review of Respiratory Disease, vol. 145, no. 5, pp. 1070-1076, 1992.

[85] W. MacNee, "An integrated approach to the treatment of pulmonary hypertension due to hypoxic lung disease," in Pulmonary Circulation: Diseases and Their Treatment, A. J. Peacock and L. J. Rubin, Eds., pp. 398-409, Arnold, London, UK, 2nd edition, 2004.

[86] K. Vonbank, R. Ziesche, T. W. Higenbottam et al., "Controlled prospective randomised trial on the effects on pulmonary haemodynamics of the ambulatory long term use of nitric oxide and oxygen in patients with severe COPD," Thorax, vol. 58, no. 4, pp. 289-293, 2003.

[87] T. A. Dernaika, M. Beavin, and G. T. Kinasewitz, "Iloprost improves gas exchange and exercise tolerance in patients with pulmonary hypertension and chronic obstructive pulmonary disease," Respiration, vol. 79, no. 5, pp. 377-382, 2010.

[88] S. Alp, M. Skrygan, W. E. Schmidt, and A. Bastian, "Sildenafil improves hemodynamic parameters in COPD—an investigation of six patients," Pulmonary Pharmacology and Therapeutics, vol. 19, no. 6, pp. 386-390, 2006.

[89] S. Holverda, H. Rietema, H. J. Bogaard et al., "Acute effects of sildenafil on exercise pulmonary hemodynamics and capacity in patients with COPD," Pulmonary Pharmacology and Therapeutics, vol. 21, no. 3, pp. 558-564, 2008.

[90] H. Rietema, S. Holverda, H. J. Bogaard et al., "Sildenafil treatment in COPD does not affect stroke volume or exercise capacity," European Respiratory Journal, vol. 31, no. 4, pp. 759-764, 2008.

[91] I. Blanco, E. Gimeno, P. A. Munoz et al., "Hemodynamic and gas exchange effects of sildenafil in patients with chronic obstructive pulmonary disease and pulmonary hypertension," American Journal of Respiratory and Critical Care Medicine, vol. 181, no. 3, pp. 270-278, 2010.

[92] N. B. Charan, "Does sildenafil also improve breathing?" Chest, vol. 120, no. 1, pp. 305-306, 2001.

[93] T. J. Torphy, "Phosphodiesterase isozymes molecular targets for novel antiasthma agents," American Journal of Respiratory and Critical Care Medicine, vol. 157, no. 2, pp. 351-370, 1998.

[94] R. S. Rao, S. Singh, B. B. Sharma, V. V. Agarwal, and V. Singh, "Sildenafil improves six-minute walk distance in chronic obstructive pulmonary disease: a randomised, double-blind, placebo-controlled trial," The Indian Journal of Chest Diseases \& Allied Sciences, vol. 53, no. 2, pp. 81-85, 2011.

[95] D. Stolz, H. Rasch, A. Linka et al., "A randomised, controlled trial of bosentan in severe COPD," European Respiratory Journal, vol. 32, no. 3, pp. 619-628, 2008.

[96] G. Valerio, P. Bracciale, and A. Grazia D’Agostino, "Effect of bosentan upon pulmonary hypertension in chronic obstructive pulmonary disease," Therapeutic Advances in Respiratory Disease, vol. 3, no. 1, pp. 15-21, 2009.

[97] G. J. Criner, "COPD and the heart: when less lung means more heart," Chest, vol. 138, no. 1, pp. 6-8, 2010.

[98] P. O. Bonetti, L. O. Lerman, C. Napoli, and A. Lerman, "Statin effects beyond lipid lowering-Are they clinically relevant?" European Heart Journal, vol. 24, no. 3, pp. 225-248, 2003. 
[99] T. M. Lee, T. F. Chou, and C. H. Tsai, "Effects of pravastatin on cardiomyocyte hypertrophy and ventricular vulnerability in normolipidemic rats after myocardial infarction," Journal of Molecular and Cellular Cardiology, vol. 35, no. 12, pp. 1449-1459, 2003.

[100] T. M. Lee, C. C. Chen, H. N. Shen, and N. C. Chang, "Effects of pravastatin on functional capacity in patients with chronic obstructive pulmonary disease and pulmonary hypertension," Clinical Science, vol. 116, no. 6, pp. 497-505, 2009.

[101] J. L. Wright, S. Zhou, O. Preobrazhenska et al., "Statin reverses smoke-induced pulmonary hypertension and prevents emphysema but not airway remodeling," American Journal of Respiratory and Critical Care Medicine, vol. 183, no. 1, pp. 50-58, 2011.

[102] G. M. Turino, R. M. Goldring, and H. O. Heinemann, "Water, electrolytes and acid-base relationships in chronic cor pulmonale," Progress in Cardiovascular Diseases, vol. 12, no. 5, pp. 467-483, 1970.

[103] M. M. Borst, M. Leschke, U. König, and H. Worth, "Repetitive hemodilution in chronic obstructive pulmonary disease and pulmonary hypertension: effects on pulmonary hemodynamics, gas exchange, and exercise capacity," Respiration, vol. 66, no. 3, pp. 225-232, 1999.

[104] D. V. Vlahakos, E. N. Kosmas, I. Dimopoulou et al., "Association between activation of the renin-angiotensin system and secondary erythrocytosis in patients with chronic obstructive pulmonary disease," American Journal of Medicine, vol. 106, no. 2, pp. 158-164, 1999.

[105] D. V. Vlahakos, K. P. Marathias, and E. N. Kosmas, "Losartan reduces hematocrit in patients with chronic obstructive pulmonary disease and secondary erythrocytosis," Annals of Internal Medicine, vol. 134, no. 5, pp. 426-427, 2001.

[106] S. Andreas, C. Hermann-Lingen, T. Raupach et al., "Angiotensin II blockers in obstructive pulmonary disease. A randomized, controlled trial," in European Respiratory Journal, vol. 27, pp. 972-979, 2006.

[107] N. W. Morrell, M. A. Higham, P. G. Phillips, B. H. Shakur, P. J. Robinson, and R. J. Beddoes, "Pilot study of losartan for pulmonary hypertension in chronic obstructive pulmonary disease," Respiratory Research, vol. 6, article 88, 2005.

[108] M. Oswald-Mammosser, R. Kessler, G. Massard, J. M. Wihlm, E. Weitzenblum, and J. Lonsdorfer, "Effect of lung volume reduction surgery on gas exchange and pulmonary hemodynamics at rest and during exercise," American Journal of Respiratory and Critical Care Medicine, vol. 158, no. 4, pp. 1020-1025, 1998.

[109] K. Kubo, T. Koizumi, K. Fujimoto et al., "Effects of lung volume reduction surgery on exercise pulmonary hemodynamics in severe emphysema," Chest, vol. 114, no. 6, pp. 15751582, 1998.

[110] T. C. Mineo, E. Pompeo, P. Rogliani et al., "Effect of lung volume reduction surgery for severe emphysema on right ventricular function," American Journal of Respiratory and Critical Care Medicine, vol. 165, no. 4, pp. 489-494, 2002.

[111] G. J. Criner, S. M. Scharf, J. A. Falk et al., "Effect of lung volume reduction surgery on resting pulmonary hemodynamics in severe emphysema," American Journal of Respiratory and Critical Care Medicine, vol. 176, no. 3, pp. 253-260, 2007.

[112] O. Bjortuft, S. Simonsen, O. R. Geiran, J. G. Field, . Skovlund, and J. Boe, "Pulmonary haemodynamics after single-lung transplantation for end-stage pulmonary parenchymal disease," European Respiratory Journal, vol. 9, no. 10, pp. 20072011, 1996.
[113] A. Kitabatake, M. Inoue, M. Asao et al., "Noninvasive evaluation of pulmonary hypertension by a pulsed Doppler technique," Circulation, vol. 68, no. 2, pp. 302-309, 1983. 


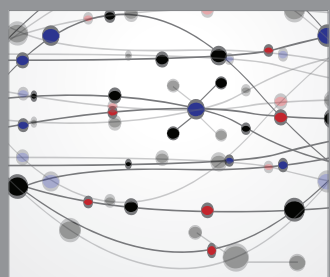

The Scientific World Journal
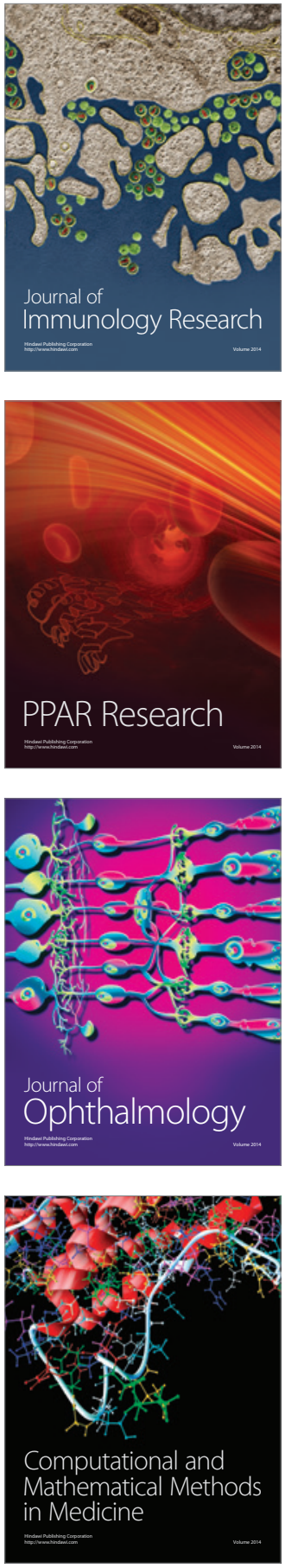

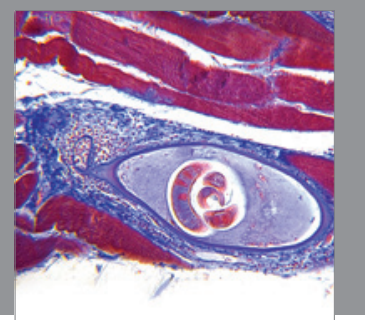

Gastroenterology

Research and Practice
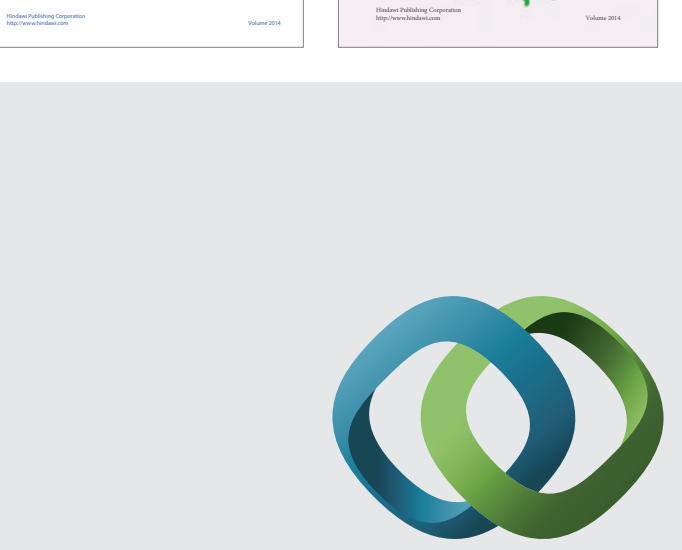

\section{Hindawi}

Submit your manuscripts at

http://www.hindawi.com
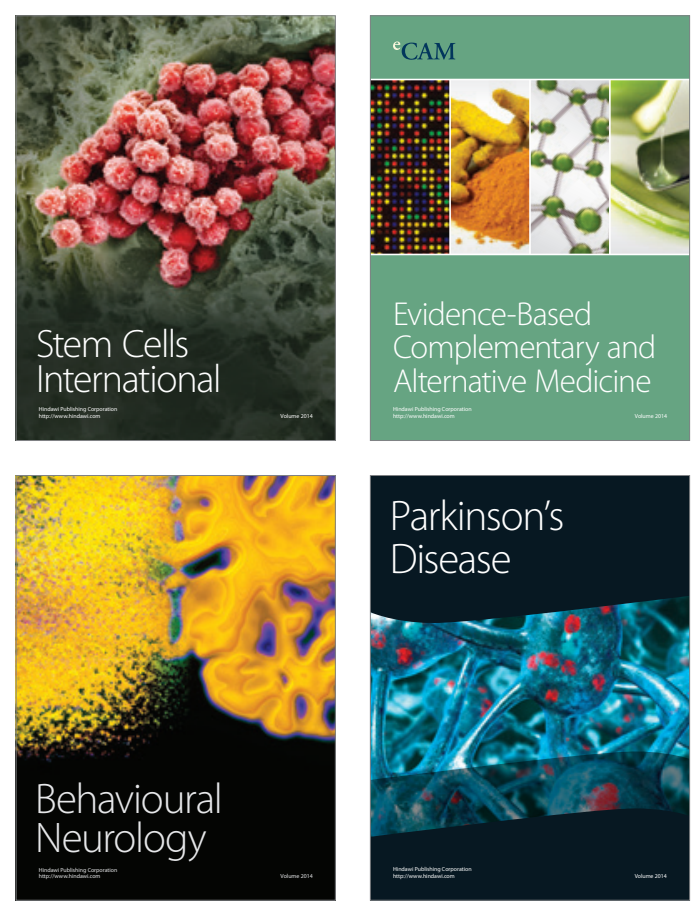

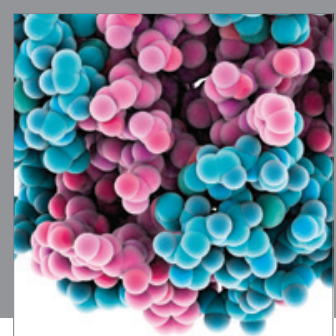

Journal of
Diabetes Research

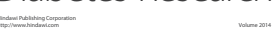

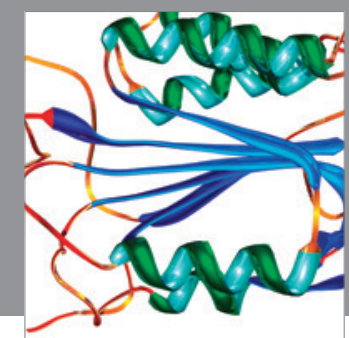

Disease Markers
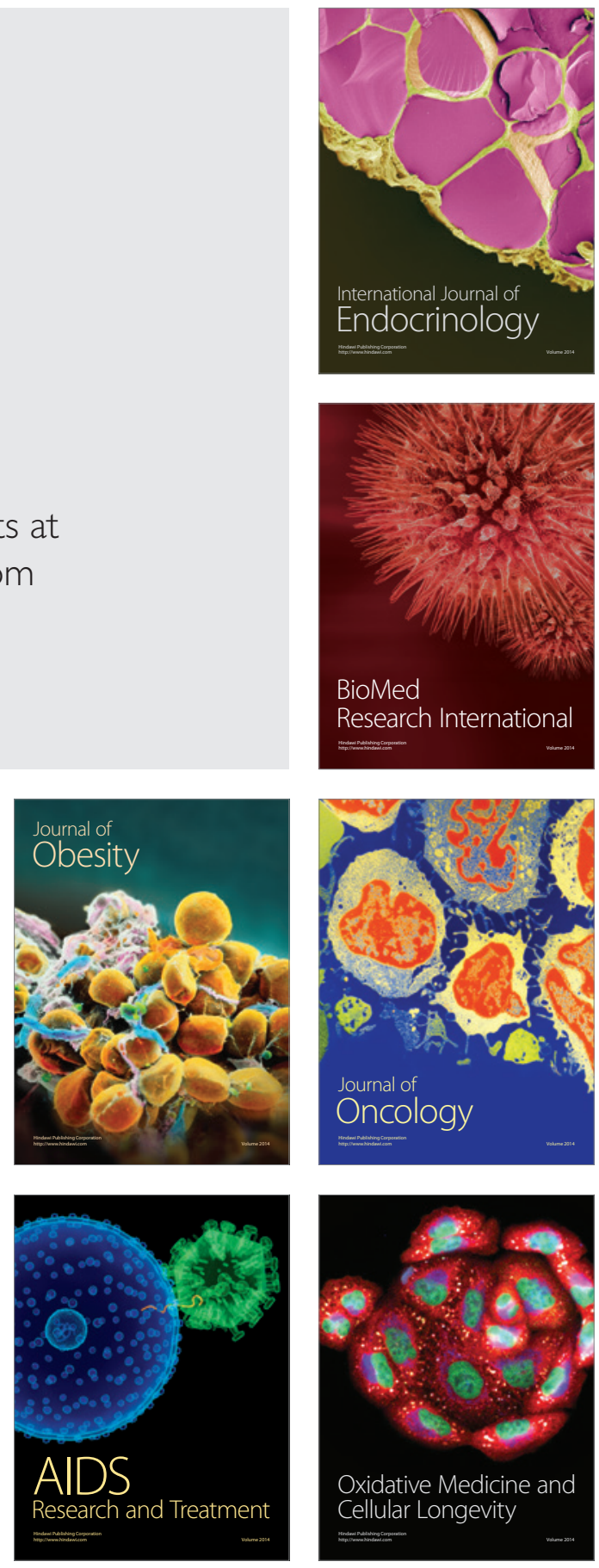